\title{
SURFACE CIRCULATION AND VENTILATION
}

\author{
Lynne D. Talley $^{(1)}, \operatorname{Rana}_{\text {Fine }}^{(2)}$, Rick Lumpkin $^{(3)}$, Nikolai Maximenko $^{(4)}, \operatorname{Rosemary~Morrow~}^{(5)}$ \\ (1) Scripps Institution of Oceanography, UCSD, 9500 Gilman Dr., La Jolla, CA 92093-0230 USA, \\ Email: ltalley@ucsd.edu \\ (2) RSMAS University of Miami, 4600 Rickenbacker Causeway Miami, FL 33149-1098 USA, \\ Email: rfine@rsmas.miami.edu \\ (3) NOAA/Atlantic Oceanographic and Meteorological Laboratory, Miami, FL 33149-1097 USA, \\ Email: Rick.Lumpkin@noaa.gov
}

(4) IPRC, School of Ocean and Earth Science and Technology, University of Hawaii at Manoa, Honolulu, HI 96822 USA, Email: maximenk@hawaii.edu

(5) СТOH, 18, av. Edouard Belin, 31401 Toulouse Cedex 9, France, Email: rosemary.morrow@legos.obs-mip.fr

\begin{abstract}
There has been tremendous progress in the last decade in observing surface circulation and its variability, mainly resulting from the longer records and higher quality of various satellite and surface drifter data sets, along with new analysis methods. Observation of upper ocean subsurface circulation is necessarily lagging behind because in situ sampling cannot match the satellite coverage; progress is being made using Argo (Array for Real-time Geostrophic Oceanography) profiling, subsurface velocities (moorings and floats), and data assimilation. Western and eastern boundary regions have very different spatial and temporal sampling requirements from the interior circulation and from each other; few are fully instrumented for longterm monitoring, but these are producing climateappropriate records of velocity, temperature and transport. Coastal circulation is increasingly monitored by high frequency radars.
\end{abstract}

Ventilation and upwelling processes connect the surface layer and underlying interior. Locally these processes are complex combinations of air-sea fluxes, convection, stratification/restratification, and frontal processes, down to the submesoscale (1 to $10 \mathrm{~km}$ ). Ongoing research ship observations provide quantitative information on formation rates and residence times, and compelling evidence of decadal ventilation changes. The Argo profiler network is beginning to produce time series that show interannual variations in major water masses. Combination of improving air-sea flux products and surface density distributions is yielding ever-improving quantitative estimates of formation rates and variability. Progress in understanding the many processes involved in ventilation has been made through regional experiments and high-resolution modeling of mixed layer and frontal processes.

Recommendations for the next decade include: maintenance of relevant existing observing systems, continued improvement of air-sea flux products, continued improvement of synthesis methods, implementation of the satellite SWOT (Surface Water Ocean Topography) and surface salinity missions, expansion of autonomous subsurface profiling to include oxygen and turbulence profiling, and implementation of local observing systems in strategic locations in boundary currents and dense water formation sites.

\section{INTRODUCTION}

This paper considers observing systems for: (1) the surface circulation and some aspects of subsurface circulation in the wind-driven gyres (Sect. 2), and (2) ventilation/upwelling processes that connect the surface and interior (Sect. 3). Tables 1 and 2 summarize the observational programs, data products, and some new results from the last decade that are the building blocks for the next decade of observations and syntheses. Principal recommendations for observations in the next decade are listed in Sect. 4 and Tab. 3.

Community white papers for OceanObs09 that are especially relevant to these two topics include those discussing surface circulation, boundary current arrays, Argo (Array for Real-time Geostrophic Oceanography) profiling, the SWOT (Surface Water Ocean Topography) satellite mission, oxygen profiling on Argo, EM (ElectroMagnetic) velocity profiling on Argo, the satellite surface salinity mission, and the OceanSITES (OCEAN Sustained Interdisciplinary Time series Environment observation System) program [1-13].

\section{SURFACE CIRCULATION}

The ocean's surface circulation is closely entwined with human activity, along with surface waves and tides. Knowledge of the circulation and its evolution has impacts on navigation, fisheries, and increasingly, prediction of ocean-atmosphere interaction. Thus there is a great deal of effort in the form of government 
funding, satellite instrumentation, in situ observations, and synthesis. Enormous progress has been made in the last decade in providing near real-time products at very high spatial resolution. Examples of discoveries in the last decade that result from the availability of such information include the spatial distribution and coherence of mesoscale eddies and eddy energy, the effect of SST gradients that result from the circulation on the overlying atmosphere, and the distribution of inertial energy in the surface layer that directly connects the wind momentum to the ocean.

The observing system as it exists today consists of satellite instrumentation, surface drifters, Argo profilers, a global tropical moored array, ship-based ADCP (Acoustic Doppler Current Profiler) profilers, coastal high-frequency radars, and a small number of intensive boundary current observatories. Together with new analysis methods, including state estimation, this system has recently born great fruit. The largest gap in the observing system, which is an accurate model of the geoid, is being aggressively pursued. The altimetry that is used to produce very high-resolution surface currents is itself of rather coarse spatial resolution: a proposed satellite mission that focuses on directly measuring much smaller spatial scales would likely provide a quantum leap in knowledge of the surface circulation (SWOT (Surface Water Ocean Topography) CWP (Community White Paper) [5]). The prospect of demise in any one of the existing components of the system should be met with great concern. The present example is the QuikSCAT (Quick Scatterometer Satellite) instrument for high-resolution winds, which ceased operating November 23, 2009 without an obvious replacement; these observations have been critically important for surface circulation and forcing products.

If we extend our focus here to the subsurface circulation, even within the upper ocean (say, top 1000 meters), there is far less information and far less analysis than for the surface circulation. There is no subsurface observing system comparable in space and time scales to the satellite-based observing system. The Argo profiling float network is the only global observing system within the water column, and its continued success is absolutely essential to progress in improving mapping of the time-dependent subsurface circulation. High-resolution state estimation appears to be the best route to providing high-resolution subsurface circulation products, combining the high-resolution surface observations and coarse-resolution Argo density profiles through a high-resolution ocean model.

Observing systems that monitor transports and water properties are essential for quantifying seasonal to climate-related variability. The RAPID/MOCHA (Rapid Climate Change/Meridional Overturning Circulation and Heatflux Array) array at $24^{\circ} \mathrm{N}$ in the Atlantic, which is measuring changes in the overturning transport of the North Atlantic, is a model of what can be achieved if the objectives are deemed worthy of the expense. Monitoring of the meridional overturning circulation in the South Atlantic is also now beginning; correlated signals of North and South Atlantic might help filter out local effects and better isolate large-scale climate variations. Monitoring of just the western boundary current portion of each major circulation system should be an objective for the next decade.

As there is a large amount of ongoing work to improve surface, and, to a lesser extent, subsurface circulation products, this summary of current progress is necessarily truncated and a moving target. The recommendations in Sect. 2.3 represent only the broadest goals.

\subsection{Surface circulation observations at the end of the 1990s}

A useful summary of the state of knowledge of the surface circulation at the end of the 1990s can be found in a chapter in a of the World Ocean Circulation Experiment (WOCE) and other global experiments of the 1990s [14].

At the end of the 1990s, the instrumentation now used for observing the surface circulation was already developed, if not fully implemented globally, and has not changed in the last decade other than in major improvements in sampling and incremental improvements in technology. The principal observing systems include: (a) density profiles that provide surface dynamic topography relative to a reference velocity level (the data set spanning the most decades), (b) altimetry from various satellites with a precise climate record beginning in 1993, (c) surface drifters drogued at a consistent depth within the full array $(15 \mathrm{~m})$, reporting their location several times a day, beginning in 1979 and expanding in earnest in the 1990s, and (d) moored velocity arrays that are more regional than these global data sets.

In the 1980s and 1990s a global analysis of the mean surface steric height, based on in situ hydrographic data, was constructed ([15-17]); the complete flow field at all levels was constructed through adjustment of the steric height. Inverse box models, whose formalism was developed in the 1970s and 1980s (see [18]), were employed in the 1990s and 2000s at a global scale to compute the large-scale circulation, with the focus on mean transports and their convergences rather than on mapping the surface circulation per se (e.g. [19] and [20]). 
In the 1990s, the newly available satellite altimetry allowed near real-time mapping of surface height anomalies, at approximately weekly resolution (e.g. SWOT CWP [5]). The first global state estimates of surface dynamic topography, incorporating global observations of satellite altimetry, a temperature-salinity climatology for the interior, and air-sea fluxes, are represented by [21], based on observations from the 1990s. This analysis was aimed at the next important step, of obtaining global fields of the time-dependent surface circulation as well as the best mean field. This state estimate approach is the basis for much of the continuing work on upper ocean circulation in the 2000s, up to the present.

Direct observations of currents in the surface layer were available globally by the end of the 1990s, from the surface drifter network deployed as part of the international TOGA (Tropical Ocean Global Atmosphere) and WOCE programs, summarized in [14]. The global mean velocity was mapped from these drifters at a spatial latitude-longitude resolution of $2^{\circ} \times 6^{\circ}$, which was the best that could be achieved globally with the then-existing data set. Higher spatial resolution was available in regions of higher drifter density, with a standard error that matched the velocities obtained from satellite altimetry. An important dynamical result from this program was demonstration of the large-scale Ekman-like response to wind stress [14 and 22].

Upper ocean moored velocity arrays were deployed in numerous key locations in the 1990s, including western and eastern boundary currents and across the tropical Pacific (TAO (Tropical Atmosphere Ocean) array). The latter was expanded to the Atlantic starting in 1997 (PIRATA (Prediction and Research Moored Array in the Atlantic) array), and became a part of the global observing system, with data release in near real-time. Full implementation of the TAO array concept in the tropical Atlantic occurred in the 2000s and is now being expanded to the Indian Ocean [23]. The ocean velocity component of the TAO time series has been less continuous and consistent than observations of temperature, salinity and atmospheric conditions, and remains so at present.

\begin{tabular}{|l|l|}
\hline \multirow{4}{*}{$\begin{array}{l}\text { Observing and } \\
\text { modeling techniques }\end{array}$} & High quality, high-resolution (mesoscale) global mapping of currents and their variability \\
\cline { 2 - 2 } & High-resolution boundary current mapping and variability \\
\cline { 2 - 2 } & Global surface drifter program \\
\cline { 2 - 2 } & Slobal profiling float program (Argo), SSOP (VOS) program \\
\cline { 2 - 2 } & Other satellite observations for blended products: high-resolution winds, SST, air-sea fluxes \\
\cline { 2 - 2 } & Satellite geoid (GRACE) \\
\cline { 2 - 2 } & High frequency coastal radar network \\
\cline { 2 - 2 } Examples of & Data assimilation (state estimation) \\
\cline { 2 - 2 } new scientific & High-resolution ocean models \\
\cline { 2 - 2 } results in the & Local process experiments \\
\cline { 2 - 2 } 2000 s & Zid-latitude influence of ocean structures, mostly SST fronts in strong currents or eddies, on the atmosphere \\
\cline { 2 - 2 } & Zonality of major ocean current structures in many places \\
\cline { 2 - 2 } & Nearly ubiquitous existence of closed eddies (cyclonic and anticyclonic) \\
\cline { 2 - 2 } & Strength of near-inertial motions in storm track regions as well as in the tropics \\
\cline { 2 - 2 } & Evolution of currents: dynamical processes and climate timescales \\
\cline { 2 - 2 } & Eddy energy mapping and relation to circulation and stratification structures \\
\hline
\end{tabular}

Table 1. Examples of surface and subsurface circulation observations, techniques and scientific results

\subsection{Surface circulation observations at the end of the 2000s}

A decade of extending the observing systems that were first implemented in the 1980s and 1990s, along with improvements in sampling and especially improvements in analysis methods and modeling, have led to surface circulation products that are truly remarkable in terms of temporal and spatial resolution.

Table 1 lists the main data products for the surface circulation, principal observing system elements, and examples of major scientific results stemming from these systems. Not included on the list are the major advances in methods for synthesizing the observations in themselves or in conjunction with numerical models; these advances are of equal importance and would not have been possible without significant resource allocations. Increasing computer power has also been an important factor.

Estimates of surface dynamic topography in the 1990s and before were derived from hydrographic profiles without direct measurements of the sea surface height or velocity. In the 2000 s, accumulation of a critical mass of uniformly high-quality drifter trajectories, many years of satellite sea level anomaly data, and new information about the geoid derived from the GRACE (Gravity Recovery And Climate Experiment) mission (Tapley et al., 2004) resulted in production of high 
resolution global mean dynamic topographies (Fig. 1a) [24] and [25]. A companion figure of the mean surface trajectories and current strength (total velocity, not just geostrophic) was also produced by [25], shown in the surface circulation CWP [2] (their Fig. 2). These new products have not only improved the accuracy of description of the large-scale geostrophic circulation but they have changed the notion of the velocity structure in frontal zones. The Gulf Stream, the Kuroshio Extension, and the Antarctic Circumpolar Current all demonstrate complex systems of narrow jets, remaining surprisingly sharp in the multi-year mean despite the high eddy activity. A global grid of quasi-zonal jet-like features emerged from the noise of previous observations [12 and 25].

While sea level variability can be easily derived from satellite altimetry data, the absolute field requires detailed spatial knowledge of the (stationary) geoid. If the temperature and salinity structures are known, their effect on surface height can be removed to sort out the effects of thermal and haline expansion from that due to mass distribution. Improving observations of the geoid are resulting from the NASA (National Aeronautics and Space Administration) GRACE and ESA (European Space Agency) GOCE (Gravity and Steady State Ocean
Circulation Explorer) missions, which together will refine the spatial resolution of the mean geoid to 100 $\mathrm{km}$. The global Argo profiling data set is providing the in situ temperature and salinity data. The international Ocean Surface Topography Mission Science Team [26] is the umbrella organization for these improvements. Their extensive activities can only be partially represented in this brief summary. Many products are available and are distributed freely through the internet. A mean surface topography map from satellite altimetry [27] is presented as Fig. 6 in the boundary current CWP (Community White Paper) [10]; this map is the prototype for ongoing surface height analyses that use the methodology introduced in that paper. (For the 2010 edition, see [28].) Maps of sea level anomaly are routinely produced by the space agencies; as an example, the monthly mean for April from Aviso (Archiving,Validation and Interpretation of Satellite Oceanographic data) [29] is shown in Fig. 1b. State estimation groups now also routinely produce surface topographies, based mainly on satellite altimetry (example in Fig. 1c). With the routine production of surface height maps and surface circulations, it is now easy to track the signature of El Niño, for instance (e.g. Fig. 1d from [30]), and potentially to detect deep convection events from space [31]. Subsurface
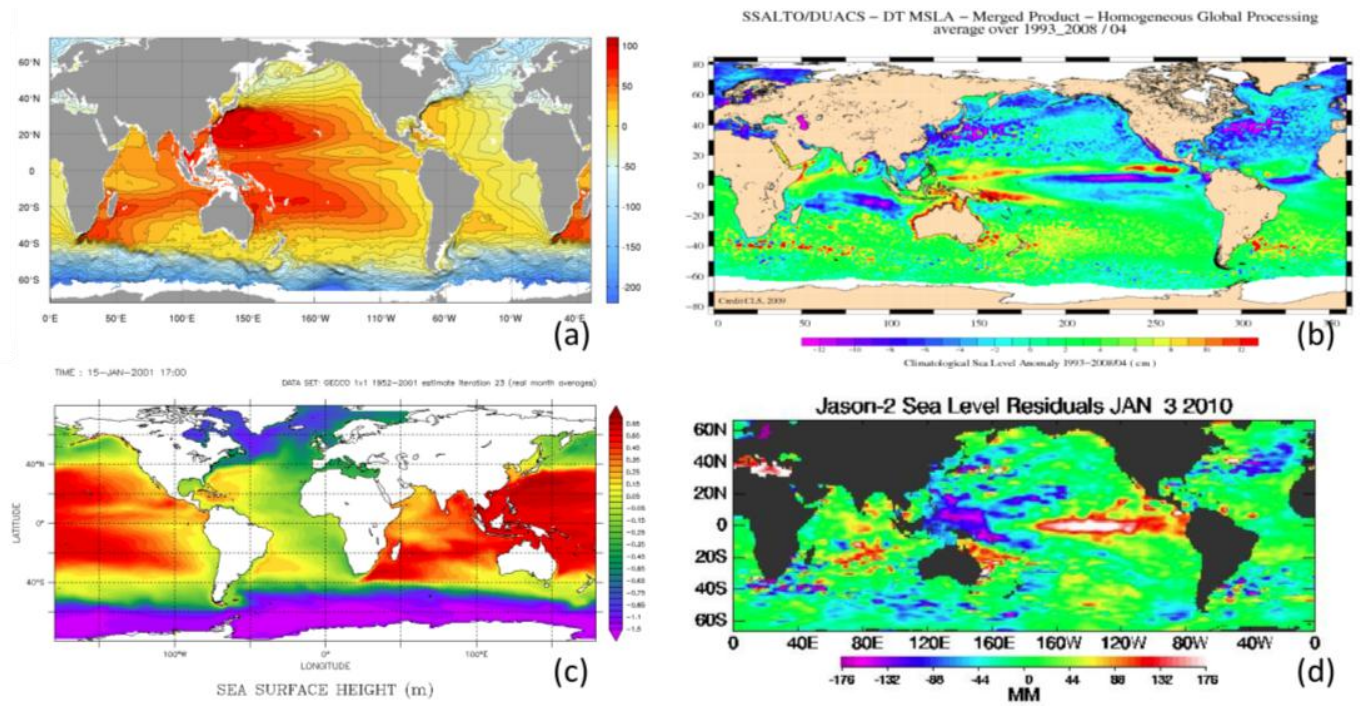

Figure 1. (a) Mean surface dynamic topography (dyn cm), with $10 \mathrm{~cm}$ contour intervals, based on surface drifters (from [25]). (b) Example of monthly climatology of sea level anomalies produced by Aviso, here for April relative to the mean for 1993 through 2008 (from [29]). (c) Example of a synoptic surface height data set from a state estimate that incorporates satellite altimetry (GECCO) (from [32]). (d) Example of surface height anomaly from the Jason-2 mission (Jan. 3, 2010), with anomalously high surface height in the tropical Pacific indicative of the ongoing El Niño (from [30]). 
circulation fields are not as readily produced. The Argo network for temperature and salinity profiles is now fully implemented globally, yielding adequate spatial information for global mapping of dynamic topography in the ocean interior (Fig. 2) [33]. The spatial resolution of this field is necessarily much coarser than that of the surface field, since there is no equivalent to the satellite altimeter for the interior ocean. The Argo-based subsurface dynamic topography at 200 dbar relative to 2000 dbar shows the familiar poleward shift of the surface subtropical geostrophic circulations with just a short distance down into the interior, as well as the much more depth-independent subpolar circulations in the North Atlantic and North Pacific, with enough data in the Southern Ocean to begin to show the northern side of the more depth-independent Antarctic Circumpolar Current. Obtaining the absolute circulation at subsurface levels follows two directions: state estimation (just as for the surface circulation) and geostrophic referencing using the absolute surface circulation obtained as described above. Additional velocity estimates come from the Argo float displacements during the submerged phase of their cycle [34].

Higher resolution gridded subsurface fields of velocity or $\mathrm{T} / \mathrm{S}$ are also being constructed from altimetry and insitu data sets. These time-evolving subsurface fields are based on statistical projections of the surface altimetric data onto vertical modes, (e.g. [35 and 36]) and corrected with in-situ Argo profiles (e.g. [37]).

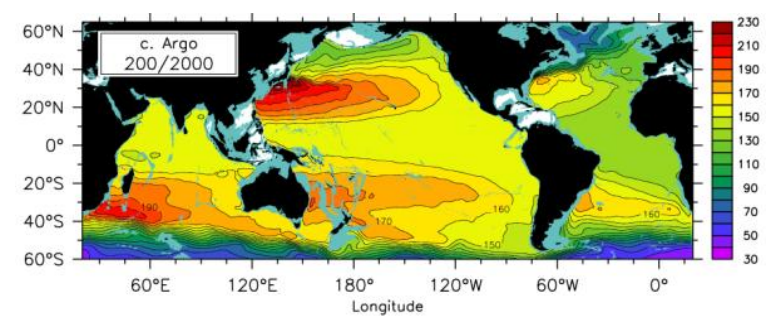

(a)

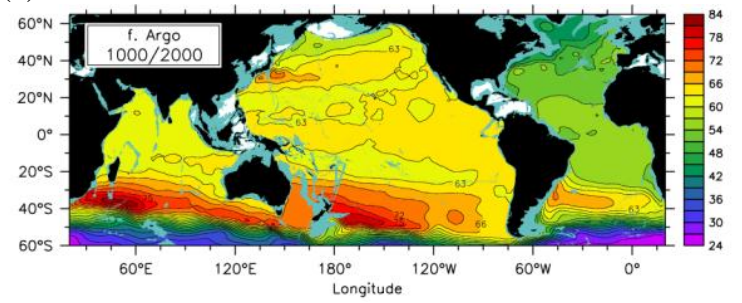

(b)

Figure 2. Steric height (dyn $\mathrm{cm})$ relative to 2000 dbar at (a) 200 dbar and (b) 1000 dbar, using mean temperature and salinity from five years of float profiles (2004-2008) [33].

With 15 years of satellite altimetry and many additional years of good surface drifter coverage, accurate maps of surface eddy kinetic energy (EKE) are now available (Fig. 3). Since the EKE calculation is based on anomalies from the mean rather than the mean field, such maps are much more easily and accurately produced from altimetry than are maps of the absolute surface height. Thus EKE maps from altimetry (e.g. Fig. 3a) were already available at the end of the 1990s, after just a few years of altimetry measurements, with more than enough accuracy and information to calculate various eddy statistics ([38], [39], [40]). EKE maps from surface drifters (Fig. 3b) are much more recent products, reflecting extension of the observing system to nearly global coverage in the 2000s. Both the altimetric and drifter EKE maps show high EKE in the expected energetic currents, and in the tropics. Interesting features of these maps, that weren't robustly apparent in the historical EKE maps based on ship drift, are the subtropical zonal bands of high EKE in the Subtropical Countercurrents (North and South Pacific, Indian Ocean, South Atlantic) and the Azores Current (North Atlantic); while current speeds are modest, the nearsurface vertical shear is large, thus generating high EKE due mainly to baroclinic instability (e.g. [41]).

The long altimetric time series also allows investigation into the time varying EKE. Indeed there is a strong interplay between changes in the large-scale circulation and the EKE response related to climate mode forcing (e.g. [42-45]).

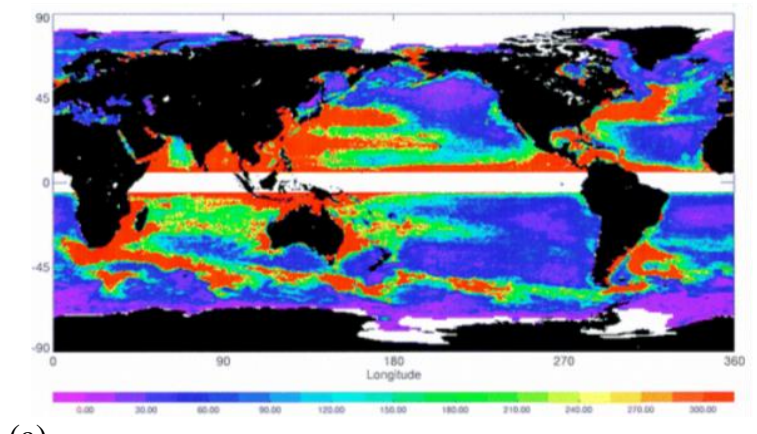

(a)

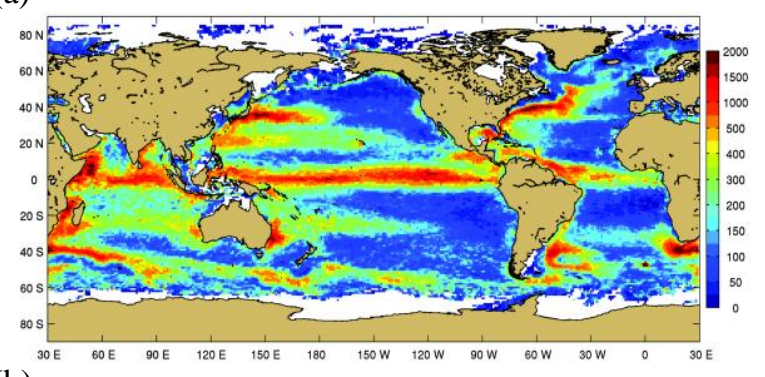

(b)

Figure 3. (a) Eddy kinetic energy $\left(\mathrm{cm}^{2} \mathrm{~s}^{-2}\right)$ from geostrophic velocities calculated from satellite altimetry from 1992 to 1998 [40]. The equatorial band is blank because geostrophic velocities cannot be calculated there. (b) Eddy kinetic energy $\left(\mathrm{cm}^{2} \mathrm{~s}^{-2}\right)$ from surface drifters [48]. 
Horizontal eddy diffusivities can now be quantified at the sea surface using the extensive Lagrangian drifter data sets, and compared with similar estimates from high-resolution numerical models. Methods for calculating the diffusivity are not standardized, but produce values that can exceed $2 \times 10^{4} \mathrm{~m}^{2} / \mathrm{s} \quad\left(2 \times 10^{8}\right.$ $\mathrm{cm}^{2} / \mathrm{s}$ ), with large spatial variation ([46] and [47]).

With the availability of satellite altimetry, highresolution satellite winds, and ocean models, including very simple ones, surface circulation is now being mapped at extremely high resolution $\left(1 / 4^{\circ}\right.$ to $\left.1 / 3^{\circ}\right)$ on time scales of several days, sufficient to see submesoscale features and current branching. High resolution $\left(1 / 4^{\circ}\right)$ surface circulation in the western tropical Pacific and near Kerguelen, resolving the mesoscale and submesoscale, respectively, is shown in Fig. 4 from [49], using methodology discussed in [50]. An example of $1 / 3^{\circ}$ daily mapping for the Gulf Stream, from the OSCAR analysis [51], which incorporates Jason altimetry and the very high-resolution QuikSCAT winds, is shown in the surface circulation CWP [2], along with several other examples from the Kuroshio [52]. The surface circulation CWP [2] describes the methodology and makes recommendations for ongoing improvements in these products. Some of these recommendations are included in the summary below.

With increasingly sophisticated data analysis techniques, the altimetry data set has been mined to find coherent eddies, which are now shown to exist in large regions of the oceans (Fig. 5, taken from [53]). The major bands of eddies resemble the mid and high latitude bands of high EKE of Fig. 3: in the western boundary currents/extensions, in the subtropics where flow is eastward, and in the Antarctic Circumpolar Current (ACC). The eddies mostly propagate almost due west relative to the mean flow; in the ACC where the flow is strongly eastward, the eddies are advected eastward. Although the eddies are strongest (highest sea surface height) in the western boundary current extensions, their populations are highest in the ACC and the mid-latitude Subtropical Countercurrents.

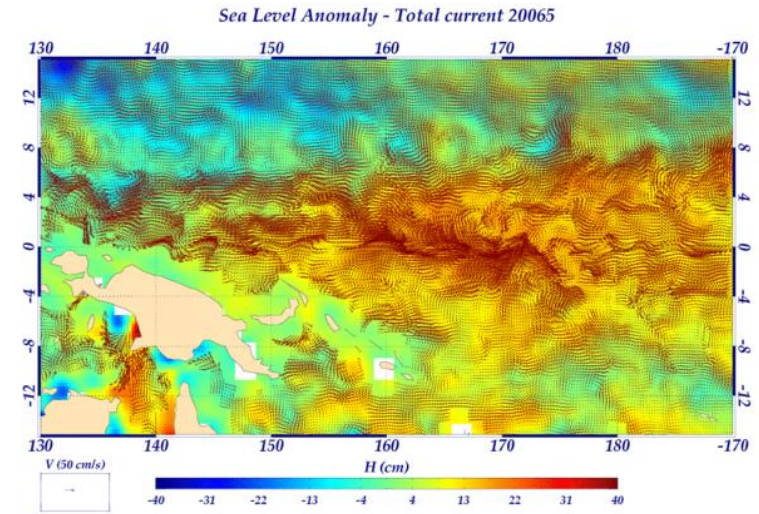

(a)

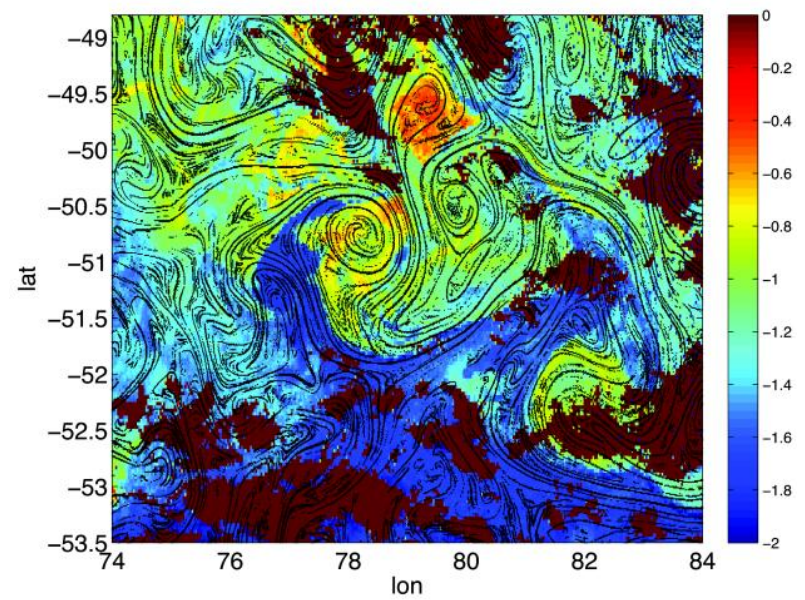

(b)

Figure 4. Examples of high-resolution $\left(1 / 4^{\circ}\right)$, nearly synoptic ( 7 day period) mapping of surface currents using altimetric surface height and scatterometry winds: (a) western tropical Pacific, showing velocity vectors overlaid on sea level anomaly $(\mathrm{cm})$ and $(b)$ Kerguelen Island, showing kinematic fronts overlaid on chlorophyll (from [49]).
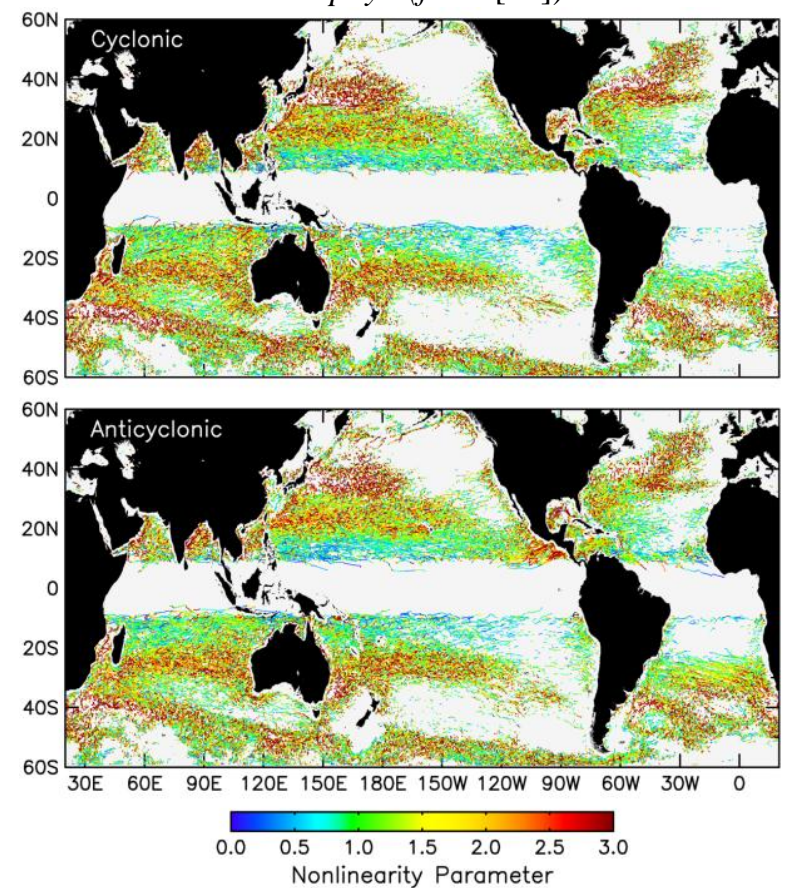

Figure 5. Tracks of coherent eddies with lifetimes of more than 4 weeks, based on altimetric sea surface height. (a) Cyclonic and (b) anticyclonic eddies, color coded by a "nonlinearity parameter", which is the ratio of velocity within the eddy compared with the eddy propagation speed. White areas indicate no eddies or trajectories within $10^{\circ}$ latitude of the equator (from [53]) 
Boundary currents pose special observational requirements because of their narrowness, high speeds and transports, variability and proximity to land, which degrades the accuracy of altimetric results (e.g. the two CWPs focusing on boundary currents [3 and 10]). The global drifter data set has begun to resolve them (see figures from [25] in the [2] CWP), but intensive, local observations are necessary to monitor these systems. Prior to the last decade, there were intensive studies of many of the Northern Hemisphere western boundary current systems (Gulf Stream, North Atlantic Current, Labrador Current, East Greenland Current, Kuroshio,
Oyashio). In the 2000s, these studies were complemented by the intensive studies and analyses of equivalent Southern Hemisphere western boundary currents (Fig. 6), including research ship surveys and moored current observations. Satellite data, mainly of SST because of its very high spatial resolution and large gradients that highlight the western boundary currents, complement these in situ observations. There is arguably now enough information about each of the mid-latitude western boundary currents and its role in maintenance of heat and other transports to permit excellent design of ongoing monitoring (see [3 and 10]).
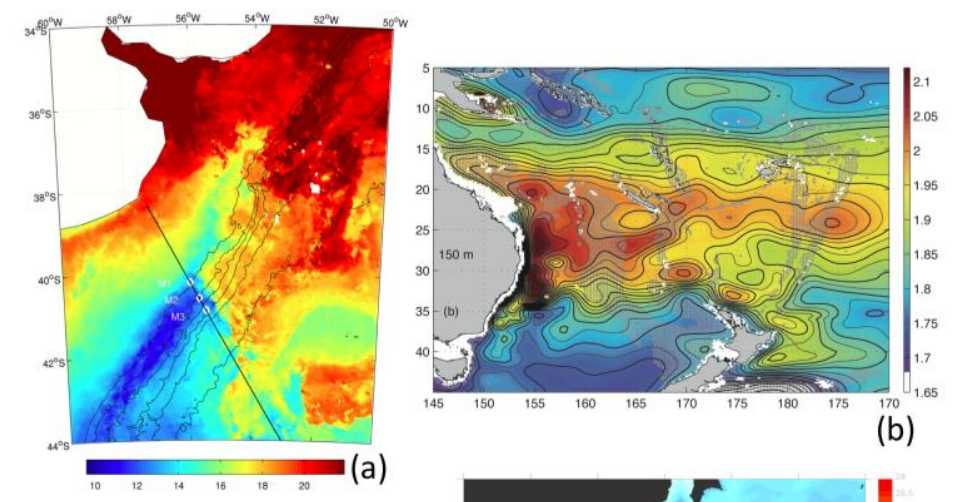

(b)
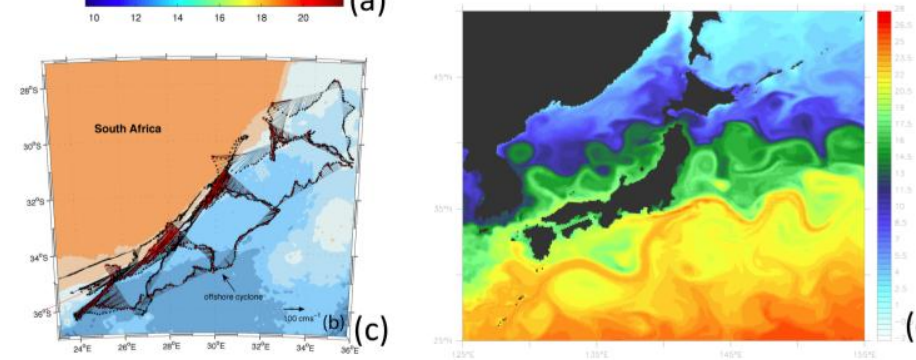

(d)

Figure 6. High-resolution observations of western boundary currents: (a) Malvinas Current [54], (b) East Australian

Current [55]), and (c) Agulhas Current [56], which were sampled and described at much higher resolution in the 2000 s than in previous decades. (d) Example of high-resolution ocean circulation model output for the Kuroshio [57].

The influence of large SST gradients on the atmosphere's surface fronts and storm track is becoming increasingly clear, with a large number of analyses and publications in the last few years ([58] and [59]; see the air-sea flux CWP [3]). The high SST (Sea Surface Temperature) gradients are associated with vigorous currents such as the Gulf Stream, Kuroshio and Agulhas. These are illustrated by [60], who used the high-resolution QuikSCAT wind observations to show the relationship between SST structures and wind curl. SST advection by the strong currents creates the large gradients. Moreover, what is likely most important for the ocean-atmosphere interaction is the heat content of the surface layer rather than simply the SST, since air- sea interaction can obliterate a very shallow SST gradient quickly. If high SST is accompanied by a thick layer of elevated temperature, then the energy source for the air-sea interaction can be sustained (e.g. [61]). Monitoring of circulation and SST in regions where gradients are shown to have the most impact on the atmosphere is recommended.

The final topic considered in this discussion of the last decade's progress in surface circulation is the demonstration and global quantification of near-inertial motions (see also the CWP discussing EM profiling on Argo [9]). These are of interest because the transfer of 

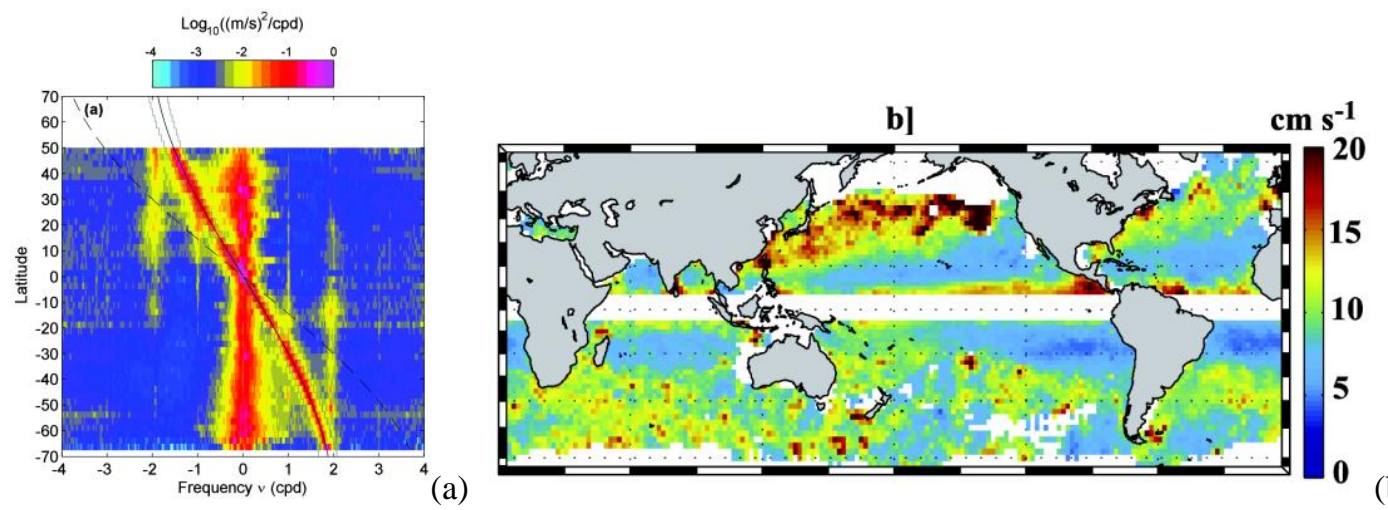

(b)

Figure 7. Near-inertial energy from surface drifters. (a) Rotary power spectra in $2.5^{\circ}$ latitude bins in the Pacific Ocean. The solid curve is the inertial frequency at each latitude; the dashed curve is twice the inertial frequency. Negative frequencies rotate counterclockwise and positive frequencies rotate clockwise [62]. (b) Average inertial current speeds $(\mathrm{cm} / \mathrm{sec})$ [63].

momentum from the wind to the ocean, especially in creation of turbulence and wind mixing of the surface layer, occurs largely through near-inertial motions. Since January 2005, surface drifter locations are obtained approximately hourly, sufficient to extract their inertial time scales. Based on the global drifter data set, near-inertial frequencies dominate at all latitudes (Fig. 7a) [62]. Mapped globally (Fig. 7b from [63]), inertial current speeds are on the order of $10 \mathrm{~cm} / \mathrm{sec}$, and up to more than $20 \mathrm{~cm} / \mathrm{sec}$ in the mid-latitude storm track regions. A particularly important finding was that the most commonly used parameterization of inertial motions from wind speeds, which is used to drive mixed layer stirring in ocean models, is seriously deficient in predicting the actual distribution of inertial motion [63].

In summary, the tremendous progress over the last decade in surface and subsurface circulation products, which have led both to important practical applications as well as to revelations about upper ocean physics, is the direct result of concerted efforts to implement the global observing system, including satellite altimetry and winds, surface drifters, and subsurface profiling floats, as well as sufficient resources (manpower, computing) to develop synthesis methods and produce near real-time data products.

\subsection{Surface circulation in the next decade}

The principal recommendation for continuing to quantify and map the surface and near-surface circulation in the next decade is to continue the programs that are already extremely successful. These include:

- Satellite altimetry and scatterometry

- Satellite geoid missions and analysis

- Global surface drifter deployments with uniform specifications for drogue capability and depth
- Global Argo profiling of temperature and salinity ([2 and 4] CWPs).

- High frequency coastal radar networks

Progress in improving these products, in terms of continued reduction of error, is coming from increasingly precise knowledge of the geoid (e.g. [27] and [26]), and ongoing activity in synthesizing the observations through simple models and state estimation (e.g. OSCAR (Ocean surface Current Analyses - Real time) [51], CTOH Centre for Topographic studies of the Oceans and Hydrosphere [49], ECCO (Estimating the Circulation \& Climate of the Ocean) [32], SCUD (Surface CUrrents from Diagnostic model) [64]).

The demise of QuikSCAT is of enormous concern; replacement of this indispensible instrument is a top priority. Similarly, if there were any threat to the altimetry, Argo profiling or surface drifter programs, surface circulation products would be seriously compromised.

Observing systems that can add significantly to the information from these global programs include:

- High-resolution altimetry (SWOT)

- Global velocity profiling (Argo augmentation)

- Regional boundary current monitoring arrays ([3 and 10] CWPs).

Surface gliders, while not proposed as a separate observing system as part of this conference, might emerge as very useful for monitoring in restricted regions such as boundary currents. With the increasingly high-resolution surface measurements, progress must be made in understanding the momentum balance in the surface layer, including the significant ageostrophic elements that are not simply the result of 
Ekman response; this should be addressed through process experiments.

No specific Community White Papers have been submitted to address improvement of subsurface circulation products. Incorporation of velocity measurements in an augmentation of Argo profiling ([9] CWP) and continued progress in high-resolution state estimation, based on continuing altimetry and Argo profiling, are likely approaches.

\section{VENTILATION}

Ocean ventilation is the process of communicating surface properties to the ocean interior. The surface layer is usually vertically mixed to some extent, and this mixed layer contains the water that moves downward. Ventilation is often, but not always, associated with an increase in density of the surface waters, and hence is usually a seasonal process in which the densest late winter surface water is the primary ventilation source. To completely describe the interior connection with the surface layer, upwelling processes are equally important to resolve.

Several distinctive processes for moving mixed layer properties into the ocean interior are described, among them: subduction, in which downward Ekman pumping and/or horizontal advection of mixed layers with spatially varying depths, combined with seasonal restratification, leaves a newly-ventilated sublayer beneath the evolving mixed layer; convection, in which buoyancy forcing creates a mixed layer that is clearly deeper than a wind-stirred mixed layer, and that is then seasonally reabsorbed into the interior; brine rejection, in which salt rejected by sea ice formation creates dense water that can flow down an undersea slope; and diapycnal diffusion at the base of the mixed layer. Convection can be divided into moderate $(150 \mathrm{~m}$ to about $600 \mathrm{~m}$ ) and deep (> $1000 \mathrm{~m}$ ), with the former occurring over relatively large regions adjacent to strong current fronts, usually referred to as mode water formation areas, and the latter occurring in specific, isolated locations [65].

Processes that move interior waters back to the sea surface are less clearly defined, but include obduction, in which Ekman suction upwells waters into the mixed layer, convection, in which waters below the mixed layer are entrained into the mixed layer, and diapycnal diffusion.

Exploring the details of each of these processes is still an open, vigorous research area.

Techniques for quantifying ventilation processes and rates include: (i) estimating the rate of flow into each isopycnal layer in the interior based on air-sea buoyancy fluxes ("Walin method" [66]), (ii) estimating the rate of flow into the interior based on properties and transports at the injection site, (iii) large-scale transport budgets for enclosed geographical regions that infer flow from the surface into interior layers based on net transformation between isopycnal layers, (iv) residence time calculations that combine the rate of flow from the surface source into a volume with the volume of that reservoir, and (v) ventilation-relevant tracer inventory methods, including quantifying the gases that invade a region from the surface layer and use of age information.

The goal of this white paper is to recommend observations for the next decade. Therefore the next Sect. (3.1) is organized around the vertical part of the water column that is observed, rather than approaching the suite of observations needed for each of these five processes and five techniques, since multiple processes and techniques can be addressed with given sets of observations in each of these regimes. These water column regimes include: (a) the air-sea interface, (b) the mixed layer, including broad-scale characterization as well as localized observations in known deep convection regions, (c) the connection between the mixed layer and the interior, and (d) the interior ocean.

In Sect. 3.2 and Tab. 2 and 3, the broad suite of observations used to study ventilation is summarized, including: air-sea fluxes of buoyancy (heat and freshwater), winds (for Ekman pumping), horizontal velocities, in situ temperature and salinity, in situ dissolved gas content (oxygen, chlorofluorocarbons, helium 3, carbon dioxide), and nutrient and tritium content. Specific experiments designed to understand various aspects of ventilation are ongoing and still very much required.

\subsection{Observations relevant to ventilation processes}

\subsubsection{Air-sea interface}

Air-sea fluxes of momentum and buoyancy drive the ocean circulation and set water properties. Both are essential inputs to mixed layer models. Thus, everimproving products for both winds and air-sea heat and freshwater flux components are essential. Wind stress products are also essential for the surface circulation analyses described in Sect. 2.

For ventilation studies, horizontal surface velocities and their convergences/divergences are required, as well as the turbulent energy input to the mixed layer that drives exchange across the base of the mixed layer. Wind stress and wind stress curl can be used to directly calculate surface layer transports and 
convergences/divergences that are used for subduction calculations, through the interaction of horizontal velocity with varying mixed layer depth, and through Ekman pumping out of the mixed layer. They can also be used in surface circulation analyses to provide more directly the surface currents at small spatial scales that can be used for these same transport and convergence calculations, rather than directly using the wind stresses.

With the QuikSCAT mission, surface wind stress with high spatial resolution was available in near real-time. [60] and [67] document the derivatives, including wind stress curl (Fig. 4 above), and provide a climatology with $1 / 4^{\circ}$ resolution. The very fine resolution matches well-known strong features of the ocean circulation and permanent front and eddy fields, and promises to yield much better local results than reanalysis winds relevant to upwelling and downwelling, and hence ventilation.

Air-sea buoyancy fluxes also drive the mixed layer deepening and are responsible for much of the restratification. Observations of these fluxes remain inadequate [e.g. the report from the Working Group on Air Sea Fluxes [68], much of which remains relevant ten years later], but there is a large amount of ongoing effort towards improving them. Recent global products that blend satellite, in situ, and reanalysis products ([69]; [70]), have significantly reduced uncertainties in the fluxes, but much work remains, possibly through increased implementation of ocean state estimates alongside the atmospheric reanalyses that produce many of the basic components of the fluxes.
With high quality surface buoyancy flux data sets, water mass formation and destruction rates in isopycnal layers can be estimated, following the Walin method, as first applied to large regions by [71]. A thorough exposition of the method and its application is found in [72]. The method can be applied to time-dependent outcrops, yielding annual cycles and multi-year time series of formation rates such that interannual variability can be estimated (e.g. [73]). Limitations to this method of inferring water mass formation directly from surface fluxes are the quality of the fluxes themselves, and diapycnal mixing within the ocean interior.

Diapycnal fluxes through the base of the mixed layer are also a mechanism for ventilating the ocean interior, and also for returning interior water to the sea surface (as evidenced in high nutrient content in the surface layer in upwelling regions). Analyses of mixing at the base of the mixed layer, driven by momentum and buoyancy fluxes, will be ever more important in understanding the connection between the surface and interior ocean. This is an area of ongoing research; see the CWP addressing ocean mixing [9].

Finally, air-sea gas exchanges are important for the overall inventories of carbon dioxide, and for inventories of gases used to estimate ventilation rates and residence times, such as chlorofluorocarbons, $\mathrm{SF}_{6}$ and oxygen. Surface layer values of these gases are not uniform, with undersaturation common in actively convecting regions, and with supersaturation near the sea surface common during restratification.

\begin{tabular}{|c|c|}
\hline \multirow[t]{5}{*}{ Data products } & Air-sea flux estimates of ventilation rates (Walin-type) \\
\hline & Mixed layer properties and circulation \\
\hline & Local deep convection studies \\
\hline & Studies of connection of mixed layer to ocean interior \\
\hline & Global scale products of ventilation-relevant properties \\
\hline \multirow{6}{*}{$\begin{array}{l}\text { Observing and } \\
\text { modeling } \\
\text { techniques }\end{array}$} & Satellite observations of SSH, SST, winds, air-sea fluxes \\
\hline & Reanalysis products yielding air-sea fluxes, winds, etc., and ocean data assimilation products \\
\hline & Global profiling float program and VOS program \\
\hline & Global scale hydrographic observations including chemical tracers \\
\hline & Local process experiments including seasonal cycles, mixing processes \\
\hline & Very high-resolution modeling \\
\hline \multirow{4}{*}{$\begin{array}{l}\text { Examples of } \\
\text { new scientific } \\
\text { results in the } \\
2000 \text { s }\end{array}$} & $\begin{array}{l}\text { Depth dependence of recently ventilated water column readily } \\
\text { recognized and quantified from T/S changes, chemistry }\end{array}$ \\
\hline & $\begin{array}{l}\text { Great complexity of processes involved in subduction and water mass formation (mode waters) near strong } \\
\text { fronts }\end{array}$ \\
\hline & Heterogeneity of mixing in the connection from mixed layer to the interior \\
\hline & Importance of mesoscale (eddies and major currents) and submesoscale (filaments and fronts) for ventilation \\
\hline
\end{tabular}

Table 2. Ventilation observations and examples for OceanObs '09 


\subsubsection{Mixed layer}

The mixed layer is the location for exchange of properties with the atmosphere, "resetting" those that are in equilibration with the atmosphere, and absorbing the momentum and buoyancy air-sea fluxes. Mapping the seasonally and interannually-evolving mixed layer and its properties is essential. Global upper ocean data sets with temperature and salinity profiles and full year coverage are used, as are surface circulation products (see Sect. 2). Prior to the 1990s and 2000s, globally distributed profiles, especially for winter, were sparse, and proxies of winter mixed layer depth were sometimes used, such as the depth of a given oxygen saturation horizon or the depth of the base of a layer of low stratification that was identified as the remnant winter mixed layer.

With observations of circulation, mixed layer depth, temperature, salinity and density, subduction and obduction from the mixed layer can be calculated.
Convection sites can be identified and time series of mixed layer properties constructed in the convecting regions.

From the 1970s into the 1990s, the principal broad-scale profiling data sets were the upper ocean thermal profile data from expendable bathythermographs (XBTs), plus all research ship-based profiles, archived at the World Data Center. Because this data set is dominated by the temperature profiles, the mixed layer climatologies published in the early to mid-2000s are based mainly on temperature [74 and 75] (Fig. 8). The sparse data coverage globally means that these products are climatological averages, combining data from all available years. Temporal evolution of the mid-ocean mixed layer with seasonal to decadal resolution is possible at Ocean Weather Ship sites and dedicated time series stations such as those near Bermuda, Hawaii, north of Iceland, and south of Honshu.
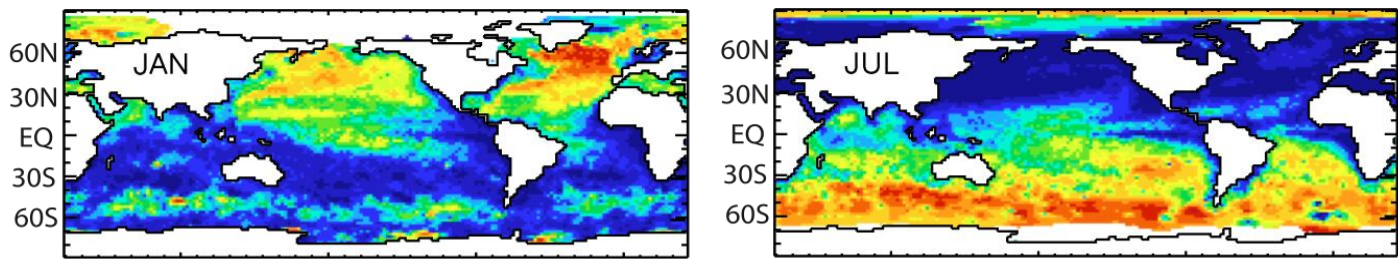

Mixed Layer Depth (m)

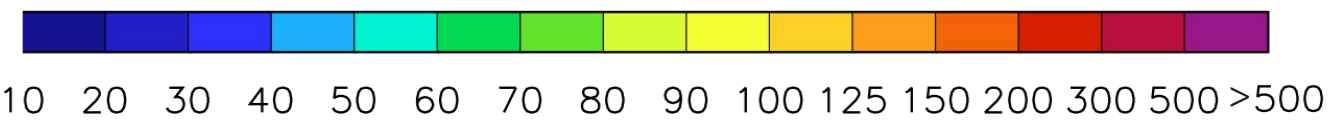

Figure 8. Global mixed layer depth climatology in late winter for both hemispheres (February and August), based on temperature profiles and a temperature threshold criterion for the mixed layer depth [75].

In the $1990 \mathrm{~s}$, broad scale profiling from autonomous floats was initiated as part of the World Ocean Circulation Experiment [76], with the network growing to global in the 2000s, as the Argo array [77]. All floats in the Argo array make a vertical profile of temperature and salinity every ten days to $1800 \mathrm{~m}$ depth. While horizontal coverage remains somewhat sparse, there are enough profiles in almost every ice-free, open ocean region to construct time series of evolving mixed layer depth, finally now allowing this critical component of ocean ventilation to be observed with full seasonal and interannual resolution. An example from [78], of a time series constructed from Argo profiles in the central Labrador Sea for the Labrador Sea where the late winter mixed layer is especially deep due to convection, is shown in the Argo (Global array of free-drifting profiling floats) program CWP [4].
The advances through the 2000s in mapping the geographic distributions of mixed layer depth, temperature, salinity and density due to the Argo array have been stunning; it is critically important to maintain this array for the foreseeable future. That said, approximately $25 \%$ of the upper ocean profiles continue to be from XBTs, especially along speciallyinstrumented merchant ship tracks, as this is the only practical way to obtain closely-spaced profiles along nearly exactly repeated tracks; such information is essential for monitoring transport changes given the ocean's mesoscale variability (order 10 to 100 kilometers), which is not resolved by the Argo profiling floats. Therefore it remains useful to incorporate temperature profiles without salinity information in mixed layer products and ventilation analysis. 


\subsubsection{Connections between the mixed layer and interior}

The simplest, older paradigms of connection between the mixed layer and interior ocean presume a smooth transition. This can be visualized as water sliding sideways along isopycnals through the "throat" of the mixed layer base, or through capping by restratification above the mixed layer, thus leaving behind a remnant of the surface layer that then becomes part of the interior water column, free to move along isopycnals and further into the interior (e.g. [79], [80] and [81]). Such models can rationalize gyre-scale distributions of properties indicative of ventilation along isopycnals, such as tritium, chlorofluorocarbons or oxygen. In addition, tracer ages can be used to estimate time scales for connection of the interior ocean back to the mixed layer and subduction rates ([82 and 83]).

However, the base of the mixed layer is a highly turbulent environment. High levels of near-inertial energy are found within and at the base of the mixed layer (Fig. 7), contributing to vertical shear and hence diapycnal mixing. Turbulence measurements include both property profiles (temperature and salinity) and also velocity observations. Observing and quantifying the connections between the mixed layer and interior over global scales would be greatly facilitated by introduction of electromagnetic (EM) profiling on the Argo floats, as recommended in the ocean mixing CWP [9].

Mixing is also horizontally heterogeneous, being more vigorous at strong fronts and eddies that are usually found in major ventilation regions, especially those with active convection (see figures and discussion in the CWP regarding ocean mixing [9]). Moreover, much observed subduction and convection occurs in and near fronts, which favor high turbulence. Subduction experiments in the 1990s and early 2000s and mode water formation experiments of the mid-2000s show actively subducting layers, marked with surface properties such as high oxygen and fluorescence typical of chlorophyll, moving downward along isopycnals from the base of mixed layer fronts (e.g. in the Azores Front [84]; at the subpolar front in the Japan/East Sea [85]; in the Gulf Stream [86]).

Upwelling is an equally important connection between the ocean interior and mixed layer. Upwelling often results in the oceans being a source of $\mathrm{CO}_{2}$ to the atmosphere, and the increase in nutrients makes upwelling regions highly productive. However, rates of upwelling are highly variable on seasonal and longer time scales, and quantifying these rates remains a challenge due to the often small quantities and small space scales involved. Progress has been made in the equatorial Atlantic where upwelling velocities, volumes and heat fluxes were calculated using the disequilibrium of helium isotopes [87].

In the last few years of the 2000s, the potential importance to ventilation of smaller spatial scale variability, defined as the submesoscale (less than order $10 \mathrm{~km}$ ), has emerged ([88], [89] and [90]). Most of the submesoscale features that have been described are in the mixed layer, and arise as instabilities of fronts and mesoscale features. Processes arising from these small features are hypothesized to facilitate greater communication with the interior below the mixed layer. They have mostly been described from high-resolution numerical models, but field observations are becoming focused on this scale. A new satellite altimetric mission that can resolve this spatial scale is in the planning stage (SWOT) (see the SWOT CWP [5]), and it is expected that the new global information about this scale will result in a major advance in understanding and quantifying the ventilation process.

\subsubsection{Interior ocean beneath the mixed layer}

Within the water column beneath the surface layer, evidence of ventilation, calculation of ventilation rates and of changes in those rates is based on in situ water properties, including temperature/salinity/density and tracers. High oxygen, high (or simply measurable) chlorofluorocarbons, tritium, anthropogenic carbon dioxide, etc., have been used with good results for calculations of spreading rates and residence times[91].

The varying volumes of water masses can be calculated given a definition of the water mass. Seasonal to interannual variations in volume can be related to changes in surface properties and forcing. Such calculations are only possible if there are enough in situ data; with the advent of global Argo profiling in the 1990s, such an approach is being realized (e.g. for the Subtropical Mode Water of the Gulf Stream system [73]). Seasonal volume changes in mode waters, as observed in the Gulf Stream region, for instance, reflect late winter formation and injection of the water mass into the upper thermocline, followed by restratification, mixing and advective export of the water mass; these processes are not yet understood.

Large, clearly measurable changes occur on interannual to decadal time scales in temperature and salinity of upper ocean waters. These often reflect changes in surface properties at the location of ventilation of these waters, although they also reflect changes in circulation away from the ventilation sources, mostly associated with changes in wind forcing. Warming of the upper ocean, attributable to anthropogenic forcing of the climate (climate change) has been observed ([92] and 
[93]). Large-scale upper ocean salinity changes have also been observed, and likely reflect a global change in the hydrological cycle [94]. Decadal changes in salinity in the northern North Atlantic have been documented at the sea surface and at numerous deep observation sites (e.g. [95] and [96]), and are continuously monitored by an international consortium (e.g. [97]) because of the potential for salinity changes to affect deep overturn.

Upper ocean declines in oxygen content have been documented in all subpolar regions (Fig. 9) (for the North Pacific [98]; for the northern North Atlantic [99]; for sectors of the Southern Ocean [100]). These primarily reflect a reduction in ventilation on the isopycnals, rather than a change in temperature (hence oxygen solubility) or change in biological utilization. The reduced ventilation is most likely associated with a shift of the mixed layer properties to lower densities, which reduces the amount of ventilation on the slightly denser isopycnals that had been previously most strongly ventilated.

Expansion of the very low oxygen zones in the tropics has been observed in each ocean [101]. As above, oxygen can change due to changes in solubility (ocean temperature at the ventilation source), saturation at ventilation, stratification and hence relative amount of ventilation on a given isopycnal, and changes in productivity and hence utilization rate $[102,103]$. The relatively larger tropical Atlantic oxygen depletion is apparently related to changes in circulation [104].

These observations of upper ocean oxygen changes were mainly made possible from the quasi-decadal research ship hydrographic surveys that routinely make oxygen observations [6]. Upper ocean oxygen changes could be monitored routinely with oxygen profilers on an Argo-like network of profiling floats. Because the changes are so widespread and apparently so coherent, and because oxygen changes also have implications for carbon in the ocean [105], a very strong recommendation for the next decade of ocean observing systems is to implement a global oxygen profiling network [7].

Research ship surveys remain the only way to measure changes in water properties below the $1800 \mathrm{~m}$ maximum depth of the current Argo network. Moreover, changes in these water properties are small enough in most regions that the higher accuracy of research ship observations is necessary for monitoring. The quasi-decadal repeats are now revealing increases in deep ocean temperature at almost all locations in the global ocean ([106] and [107]). The changes are only relatively large in the vicinity (hundreds to thousands of kilometers) of the deep water sources, thus reflecting changes in ventilation properties -volume, temperature and density. Deep water temperature changes much farther from ventilation sources presumably reflect an adjustment of the deep ocean circulation [106]. Continued monitoring of these changes requires continued highly accurate research ship surveys (see the CWP recommending hydrographic observations [6]). Furthering the development of deeper reaching Argo floats with high precision for the deep oceans is also recommended.
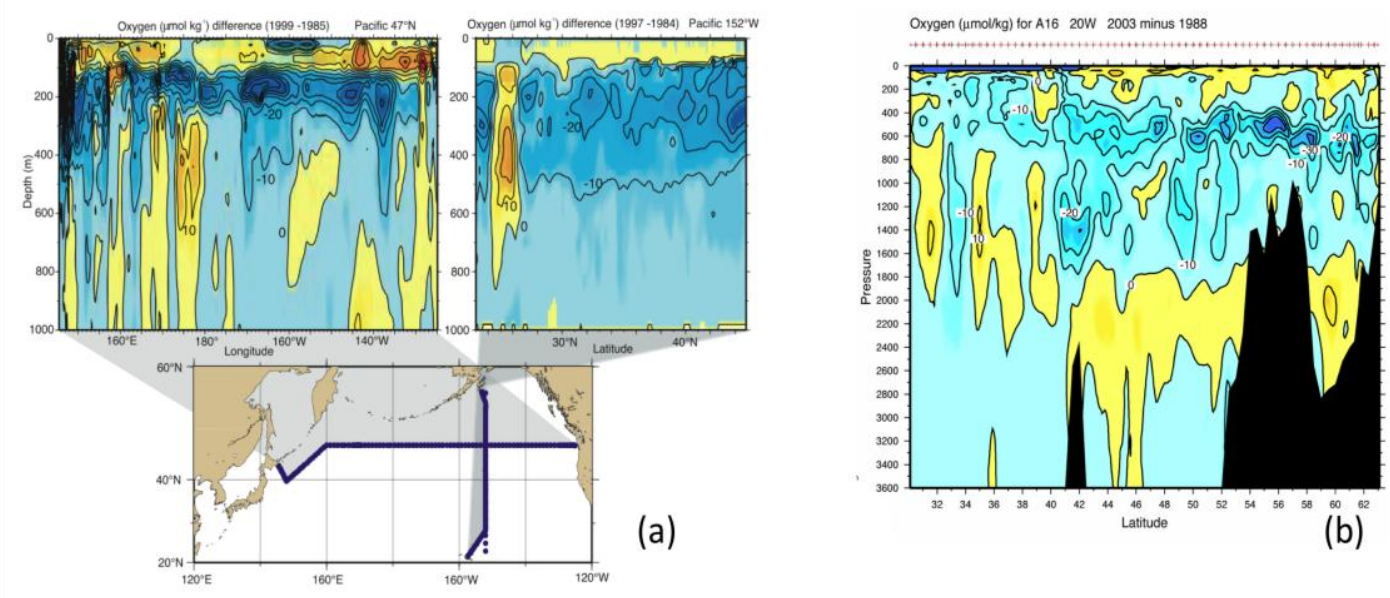

Figure 9. Upper ocean oxygen changes over the past several decades. Differences were computed on isopycnals and

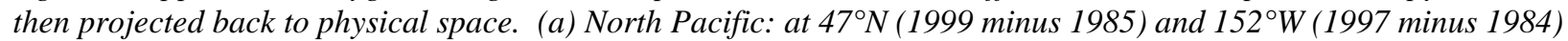

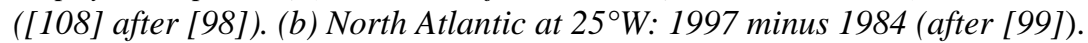


Variations in volumes and transports of newly-formed deep waters are especially interesting in the Nordic Seas, North Atlantic and Southern Ocean, where interannual to decadal variations in deep water properties thousands of kilometers downstream of their sources in these oceans are readily apparent (e.g. [108] and [109]). Adjustment of the circulation and surface properties to changes in deep water sources and transports is part of the climate system, and is considered important to observe and possibly predict. Hence deep observation systems that can capture changes in volume, transport and properties of deep waters are necessary. Through the 1990s and 2000s, a number of focused observation systems were put in place in the northern North Atlantic, from the Florida Current northward to the Nordic Seas. These include intensive transport monitoring, temperature/salinity monitoring, and regular observations of transient tracers such chlorofluorocarbons (Figs. 10b, 10c). The boundary current CWP [11] describes these North Atlantic arrays, which include the Rapid/Mocha array at $24^{\circ} \mathrm{N}$, intensive observations in the Labrador Sea, in the North Atlantic Current, at all straits along the Greenland-Iceland-Faroe ridge, and in the Nordic Seas.

Ventilation fluxes and residence times of interior ocean water masses can be computed from observations of transient tracers such as chlorofluorocarbons (CFCs) [110 and 111]. Even with a steady-state circulation and no change in the seasonal cycle of forcing, the CFC distribution would change because of their timedependent anthropogenic atmospheric source. Knowing the source and measuring the CFC inventory, water mass formation rates can be calculated [112-114]. The global map of the water column inventory of CFCs (Fig. 10a) reflects the relative amount of ventilated water found at each geographic location; the regions of especially thick mixed layers (mode waters) in the Antarctic Circumpolar Current region and in the North Atlantic dominate the pattern. This pattern of the passive CFC tracer is strongly related to patterns of anthropogenic $\mathrm{CO}_{2}$ content [115], which have major implications for the ocean's role in climate change.

Variations in CFC content in the repeatedly sampled northern North Atlantic have been used to document changes in the Labrador Sea Water properties (the intermediate/deep water that is ventilated through deep convection in the Labrador Sea) (e.g. Fig. 10b, c). A formation rate for that water mass can be calculated from changes in the water column inventory (like that of Fig. 10a but for isopycnal layers) from one decade's hydrographic survey to the next. Such measurements can only be made from research ships ([6] CWP) and their continuation is recommended, as the CFC and also $\mathrm{SF}_{6}$ signals continue to invade further into the global ocean, providing an indication of time since ventilation and a means of quantifying formation rates.

\subsubsection{Process experiments}

Process experiments are not part of the observing system, but breakthroughs in understanding from these regional experiments inform the needs for future observations. It is difficult and probably inadvisable to predict from this vantage point in 2009-2010 the types of process experiments focused on ventilation that will be proposed and implemented in the next decade. A decade ago, with the end of the World Ocean Circulation Experiment and the beginning of CLIVAR (Climate Variability and Predictability) and the global ocean observing system, it would have been equally difficult to predict the directions taken during the ensuing ten years.

However, it is fair to say that much still remains to be learned about each of the ventilation processes described above. At this time, particularly strong efforts are being proposed for study of the details of connection between the mixed layer and interior, relative to the physics of the mixed layer at very small scales (submesoscale). Ocean mixing/turbulence observations have come to the fore, at all depths and locations in the ocean; of particular usefulness for ventilation studies will be those focused on the mixed layer and pycnocline. Ongoing studies regarding mode water formation and destruction promise to provide much more information about these processes. Mid-latitude feedbacks between high gradients in SST (hence surface layer heat content and thickness, which are related to ventilation) and the overlying atmosphere are now understood to be important, and could lead to focused process experiments. Eddy-resolving observations and models in deep convection regions such as the Labrador Sea promise to lead to continued progress in understanding the preconditioning for deep convection. 

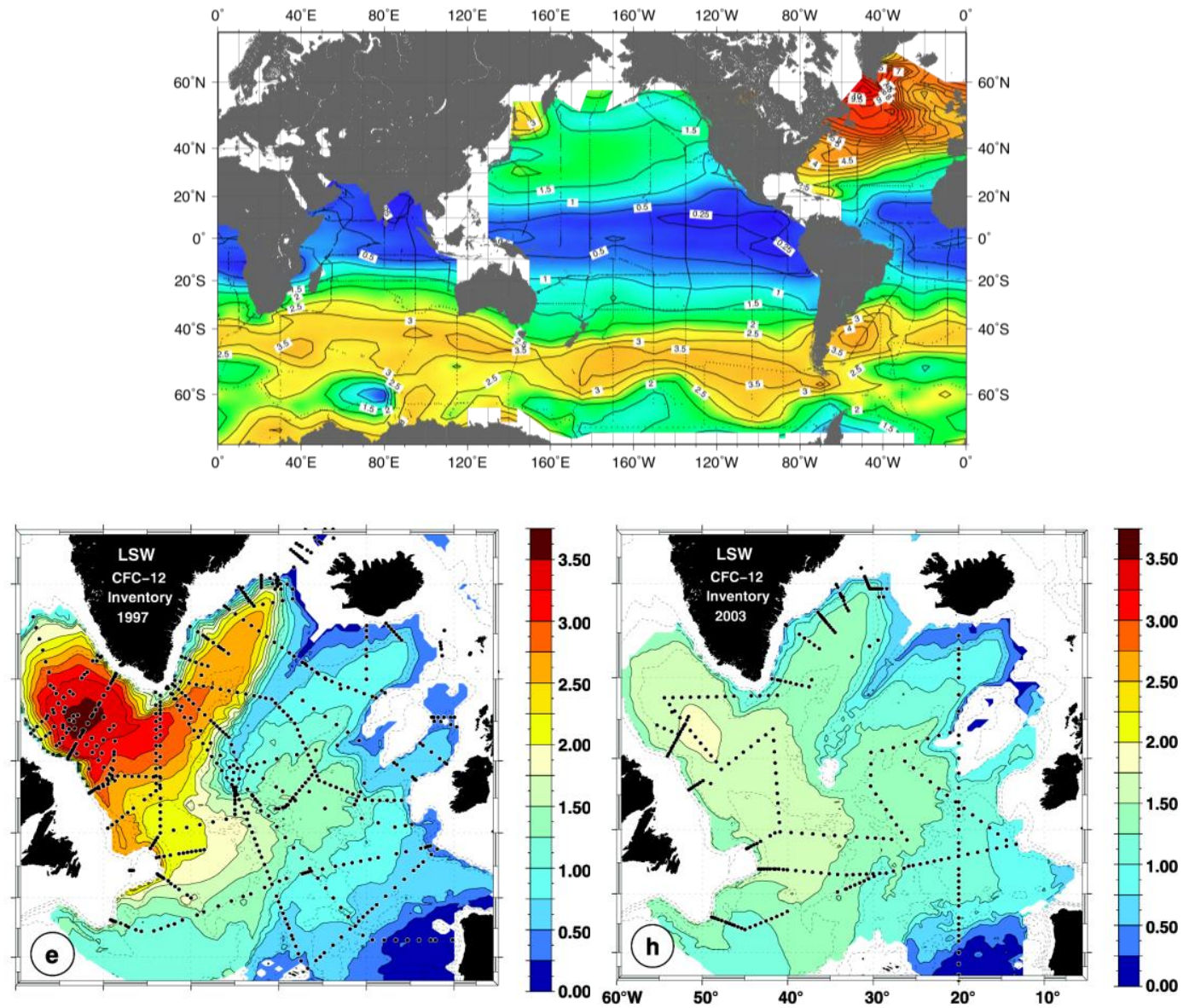

Figure 10. (a) Global chlorofluorocarbon-11 water column inventory (moles $/ \mathrm{km}^{2}$ ) [116]). (b,c) Chlorofluorocarbon-12 inventory $\left(\right.$ moles $\left./ \mathrm{km}^{2}\right)$ in the "classic" Labrador Sea Water layer in the North Atlantic in 1997 and in 2003 [117].

\subsection{Ventilation studies in the next decade}

Major progress in understanding and quantifying ventilation globally will be possible in the next decade, building on the existing observing system. Key elements of the existing observing system are listed in Tab. 3 and are not re-enumerated here.

Three evolving or new areas of high priority that are highly likely to be implemented based on ongoing progress and international space agency planning are:

- Improved air-sea flux products

- Developing higher-resolution altimeter-based SSH such as SWOT ([5] CWP)

- Satellite surface salinity observations and blended products ([8] CWP)

- High-resolution state estimation

Global air-sea flux products are not yet accurate enough for ventilation studies, although recent improvements are encouraging, and therefore this is listed as a high priority for the next decade. The salinity resolution of the planned satellite observations will not be sufficient to replace in situ surface salinity observations, including those from the Argo array, but blending of the satellite and in situ data sets will yield a product with more space and time information than is available through the in situ products ([8] CWP).

New global observations that could result in greatly improved ventilation description include:

- Regular in situ profiling in ice-covered regions

- Regular global in situ profiling of oxygen

- Regular global in situ profiling of velocity/turbulence

These are not yet planned, although there are enthusiastic communities that are pursuing these augmentations of the highly successful Argo network. However, there is concern that changes to the present Argo configuration might result in degradation of the network, given that it has only recently been fully implemented. Discussion of new profiling observations could thus be framed in terms of a new network of 
profiling floats, in an experimental mode, whose temperature and salinity profiles would augment the Argo data set, but whose implementation would not endanger the existing network until it is clear that it will be sustained for the foreseeable future.

Monitoring of localized water mass formation processes is also important. The global networks just described are appropriate for the broad-scale, open ocean connections between the mixed layer and interior (mode waters, subduction, obduction), and may also be mostly adequate for deeper open ocean convection. However, some localized ventilation processes, especially in shallow water regions, cannot be observed with these techniques. For instance, dense water formation through brine rejection over continental shelves requires local observations. Thus

- Monitoring of dense water formation sites with dedicated arrays (moorings, AUVs) is recommended.

\section{SUMMARY OF RECOMMENDATIONS}

Surface circulation analyses have already reached an enviable level of success because of the observational and computing resources, practical motivation, and funding that have been available for the last decade. Simply put, the surface can be observed with satellites, and this has made accurate, relatively high-resolution products possible. The proposed SWOT mission will extend this resolution to even shorter spatial scales. The surface drifter network is of equal importance for surface circulation analyses because it provides in situ calibration of the satellite observations and because its temporal and spatial resolution differ from those of the satellites, i.e. it provides information about much higher frequency motions. The high frequency, high spatial resolution of the surface drifter and SWOT data sets will require general progress in understanding the momentum balance of the mixed layer since both will observe significant ageostrophic components.

The principal recommendations for surface circulation are to maintain the existing observing systems, based around satellites and surface drifters, to extend observations to the submesoscale (SWOT), and to continue to work to improve diagnostic models that incorporate these data, and which have already proven invaluable in extending the data sets to much higher spatial and temporal resolution than is available in any given part of the data set. For the subsurface circulation in the upper ocean, new tools (such as velocity profilers) and methods need to be implemented on a massive scale.

Ventilation analyses cover a much broader range of phenomena, and occupy much more of the water column. It is unlikely that there will ever be interior ocean observations that can reach the spatial resolution of satellites, but the Argo profiling network, intensive routine monitoring of dense water formation areas and overflows, quasi-decadal research ship surveys that include oxygen and tracers, and specialized process experiments have led to numerous new insights about ventilation in the last decade. These new understandings should permit ongoing monitoring of ventilation processes, with at least monthly resolution based on the temporal resolution of the most accurate air-sea flux products and Argo profiling.

The principal recommendations for improving ventilation analyses include continued scientific development through process experiments, continued improvements in air-sea fluxes, implementation of two planned satellite missions (SWOT and surface salinity), active consideration of routine profiling of oxygen and velocity, and extension of dense water formation monitoring to all important sites. 


\begin{tabular}{|c|c|c|}
\hline & Data products & Measurements \\
\hline \multirow{10}{*}{$\begin{array}{l}\text { Present (2009-2010), of } \\
\text { high priority for } \\
\text { continuation and } \\
\text { improvement in } 2010 \text { - } \\
2020\end{array}$} & $\begin{array}{l}\text { Wind stress (high-resolution), air-sea fluxes of heat } \\
\text { and freshwater }\end{array}$ & $\begin{array}{l}\text { QuikSCAT, satellite SST, water vapor, other } \\
\text { observations required for atmospheric } \\
\text { reanalyses }\end{array}$ \\
\hline & $\begin{array}{l}\text { SST (high spatial resolution), SSH (mesoscale } \\
\text { resolution) }\end{array}$ & Satellite observations \\
\hline & Ocean color & Satellite observations \\
\hline & $\begin{array}{l}\text { Surface layer velocities, including inertial } \\
\text { component (6-hourly) }\end{array}$ & $\begin{array}{l}\text { Satellite SSH, surface drifters, models } \\
\text { including state estimation that also incorporate } \\
\text { satellite winds }\end{array}$ \\
\hline & $\begin{array}{l}\text { Mixed layer depth, temperature, salinity, density } \\
\text { (quasi-weekly) }\end{array}$ & Argo profiling floats $(\mathrm{T}, \mathrm{S}), \mathrm{VOS}$ (mostly T) \\
\hline & Pycnocline velocities (quasi-weekly) & $\begin{array}{l}\text { Satellite SSH, Argo profiling floats (T,S), state } \\
\text { estimation }\end{array}$ \\
\hline & $\begin{array}{l}\text { Pycnocline temperature, salinity, density (quasi- } \\
\text { weekly) }\end{array}$ & Argo profiling floats (T,S), VOS (mostly T) \\
\hline & $\begin{array}{l}\text { Deep temperature, salinity, density (weekly to } \\
\text { decadal) }\end{array}$ & $\begin{array}{l}\text { Moorings (T, S), research ship hydrographic } \\
\text { surveys }\end{array}$ \\
\hline & $\begin{array}{l}\text { Oxygen, chlorofluorocarbon, carbon parameters } \\
\text { (full water column) }\end{array}$ & Research ship hydrographic surveys \\
\hline & $\begin{array}{l}\text { Monitoring of deep overflows and Deep Western } \\
\text { Boundary Currents downstream of water mass } \\
\text { formation regions }\end{array}$ & Moorings, regular research ship surveys \\
\hline \multirow{8}{*}{$\begin{array}{l}\text { Recommended } \\
\text { additional or improved } \\
\text { for } 2010-2020\end{array}$} & Boundary current monitoring & Moorings and ship observations \\
\hline & Higher accuracy air-sea fluxes (daily or better) & $\begin{array}{l}\text { Continued refinement of methods for } \\
\text { combining satellite, in situ, and reanalysis } \\
\text { information; implementation of global array of } \\
\text { in situ air-sea flux validation sites }\end{array}$ \\
\hline & $\begin{array}{l}\text { Higher spatial resolution SSH (submesoscale } \\
\text { resolution) }\end{array}$ & SWOT \\
\hline & Sea surface salinity & Satellite SSS \\
\hline & $\begin{array}{l}\text { Turbulent mixing estimates in and below mixing } \\
\text { layer (quasi-weekly) }\end{array}$ & Profiling float EM measurements \\
\hline & Mixed layer oxygen (quasi-weekly) & Profiling float oxygen measurements \\
\hline & Pycnocline oxygen (quasi-weekly) & Profiling float oxygen measurements \\
\hline & $\begin{array}{l}\text { Monitoring of each of the important localized deep } \\
\text { water formation sites, including those in ice-covered } \\
\text { regions }\end{array}$ & Moorings, regular AUV surveys \\
\hline
\end{tabular}

Table 3. Present and recommended data products and observations for both surface circulation and ventilation studies

\section{REFERENCEI}

1. Wilson, S. \& Co-Authors (2010). "The Ocean Surface Topography Constellation: The Next 15 Years in Satellite Altimetry" in these proceedings (Vol. 2), doi:10.5270/OceanObs09.cwp.92.

2. Dohan, K. \& Co-Authors (2010). "Measuring the Global Ocean Surface Circulation with Satellite and In Situ Observations" in these proceedings (Vol. 2), doi:10.5270/OceanObs09.cwp.23.

3. Conkright Gregg, M., Newlin, M., LeDuc, S., Keeley, R. and D'Adamo, N., (2010)."Ocean and Coastal Data Stewardship" in these proceedings (Vol. 2), doi:10.5270/OceanObs09.cwp.18.

4. Freeland, H. \& Co-Authors (2010)."Argo - A Decade of Progress" in these proceedings (Vol. 2), doi:10.5270/OceanObs09.cwp.32.
5. Fu, L. \& Co-Authors (2010). "The Surface Water and Ocean Topography (SWOT) Mission" in these proceedings (Vol. 2), doi:10.5270/OceanObs09.cwp.33.

6. Hood, M. \& Co-Authors (2010). "Ship-Based Repeat Hydrography: A Strategy for a Sustained Global Program." in these proceedings (Vol. 2), doi:10.5270/OceanObs09.cwp.44.

7. Gruber, N. \& Co-Authors (2010). "Adding Oxygen to Argo: Developing a Global In-Situ Observatory for Ocean Deoxygenation and Biogeochemistry" in these proceedings (Vol. 2), doi:10.5270/OceanObs09.cwp.39.

8. Lagerloef, G. \& Co-Authors (2010). "Resolving the Global Surface Salinity Field and Variations by Blending Satellite and In Situ Observations" in these proceedings (Vol. 2), doi:10.5270/OceanObs09.cwp.51. 
9. MacKinnon, J. \& Co-Authors (2010). "Using Global Arrays to Investigate Internal Waves and Mixing" in these proceedings (Vol. 2), doi:10.5270/OceanObs09.cwp.58'

10. Send, U. \& Co-Authors (2010). "A Global Boundary Current Circulation Observing Network" in these proceedings (Vol. 2), doi:10.5270/OceanObs09.cwp.78.

11. Send, U. \& Co-Authors (2010). "OceanSITES" in these proceedings (Vol. 2), doi:10.5270/OceanObs09.cwp.79.

12. Scott, R. \& Co-Authors (2010). "Satellite Altimetry and Key Observations: What We've Learned, and What's Possible with New Technologies" in these proceedings (Vol. 2), doi:10.5270/OceanObs09.cwp.76.

13. Shum, C. \& Co-Authors (2010). "Geodetic Observations of the Ocean Surface Topography, Geoid, Currents, and Changes in Ocean Mass and Volume" in these proceedings (Vol. 2), doi:10.5270/OceanObs09.cwp.80.

14. Niiler, P. P. (2001). The world ocean surface circulation. In Ocean Circulation and Climate. Eds. G. Siedler, J. Church, \& J. Gould. Academic Press, London, 193204.

15. Reid, J. L. (1994). On the total geostrophic circulation of the North Atlantic Ocean: Flow patterns, tracers, and transports. Progress in Oceanography 33, 1-92.

16. Reid, J. L. (1997). On the total geostrophic circulation of the Pacific Ocean: flow patterns, tracers, and transports. Progress in Oceanography 39, 263-352.

17. Reid, J. L. (2003). On the total geostrophic circulation of the Indian Ocean: flow patterns, tracers, and transports. Progress in Oceanography 56, 137-186.

18. Wunsch, C. (1996). The Ocean Circulation Inverse Problem. Cambridge University Press, Cambridge, $442 \mathrm{pp}$.

19. Macdonald, A. M. \& Wunsch, C. (1996). An estimate of global ocean circulation and heat fluxes. Nature 382, 436-439.

20. Ganachaud, A. \& Wunsch, C. (2000). Improved estimates of global ocean circulation, heat transport and mixing from hydrographic data. Nature 408, 453-457.

21. Stammer, D. et al. (2002). Global ocean circulation during 1992-1997, estimated from ocean observations and a general circulation model. J. Geophys. Res. 107, 3118, doi:10.1029/2001jc000888.

22. Ralph, E. A. \& Niiler, P. P. (1999). Wind-Driven Currents in the Tropical Pacific. Journal Of Physical Oceanography 29, 2121-2129.
23. TAO (2010). TAO / TRITON data display and delivery. NOAA Pacific Marine Environmental Laboratory. <http://www.pmel.noaa.gov/tao/disdel/disdel.html > (accessed January 10, 2010).

24. Niiler, P. P., Maximenko, N. A. \& McWilliams, J. C. (2003). Dynamically balanced absolute sea level of the global ocean derived from near-surface velocity observations. Geophysical Research Letters 30, doi:10.1029/2003GL018628.

25. Maximenko, N. et al. (2009). Mean Dynamic Topography of the Ocean Derived from Satellite and Drifting Buoy Data Using Three Different Techniques*. Journal of Atmospheric and Oceanic Technology 26, 1910-1919, doi:10.1175/2009JTECHO672.1.

26. NASA (2008). Ocean Surface Topography Mission/Jason-2: Watching over our ocean. NASA Jet Propulsion Laboratory. <http://eospso.gsfc.nasa.gov/ftp_docs/OSTMbrochure2 0081009.pdf> (accessed January 10, 2010).

27. Rio, M. H. \& Hernandez, F. (2004). A mean dynamic topography computed over the world ocean from altimetry, in situ measurements, and a geoid model. $J$. Geophys. Res. 109, C12032, doi:10.1029/2003jc002226.

28. CNES/CLS. (2010).Aviso Combined Mean Dynamic Topography, <http://www.aviso.oceanobs.com/en/data/products/auxi liary-products/mdt/index.html>.

29. Aviso (2010). AVISO. CNES and CLS. <http://www.aviso.oceanobs.com/es/data/products/seasurface-height-products/global/msla-meanclimatology> (accessed January 10, 2010).

30. NASA (2010). Ocean surface topography from space. NASA Jet Propulsion Laboratory. <http://topexwww.jpl.nasa.gov/> (accessed January 10, 2010).

31. Herrmann, M., Bouffard, J. \& Bèranger, K. (2009). Monitoring open-ocean deep convection from space. Geophysical Research Letters 36, L03606, doi:10.1029/2008gl036422.

32. ECCO (2007). Estimating the climate and circulation of the ocean. ECCO Consortium. <http://www.eccogroup.org $>$ (accessed January 10, 2010).

33. Roemmich, D. \& Gilson, J. (2009). The 2004-2008 mean and annual cycle of temperature, salinity, and steric height in the global ocean from the Argo Program. Progress In Oceanography 82, 81-100.

34. Lebedev, K., Yoshinari, H., Maximenko, N. A. \& Hacker, P. W. (2007). YoMaHa'07: Velocity data assessed from trajectories of Argo floats at parking 
level and at the sea surface. IPRC Technical Note 4.2, 16.

35. Sun, C. \& Watts, D. R. (2001). A circumpolar gravest empirical mode for the Southern Ocean hydrography. $J$. Geophys. Res. 106, 2833-2855, doi:10.1029/2000jc900112.

36. Swart, S. \& Speich, S. (2010). An altimetry-based gravest empirical mode south of Africa: 2. Dynamic nature of the Antarctic Circumpolar Current fronts. J. Geophys. Res. 115, C03003, doi:10.1029/2009jc005300.

37. Larnicol., G. et al. (Year). The global observed ocean products of the French Mercator project. 'In these proceedings (Vol.' edn 6 (ESA CNES).

38. Stammer, D. (1997). Global Characteristics of Ocean Variability Estimated from Regional TOPEX/POSEIDON Altimeter Measurements. Journal Of Physical Oceanography 27, 1743-1769.

39. Stammer, D. (1998). On Eddy Characteristics, Eddy Transports, and Mean Flow Properties. Journal Of Physical Oceanography 28, 727-739, doi:10.1175/15200485(1998)028<0727:OECETA>2.0.CO;2.

40. Ducet, N., Le Traon, P. Y. \& Reverdin, G. (2000). Global high-resolution mapping of ocean circulation from TOPEX/Poseidon and ERS-1 and -2. J. Geophys. Res. 105, 19477-19498, doi:10.1029/2000jc900063.

41. Qiu, B., Scott, R. B. \& Chen, S. (2008). Length Scales of Eddy Generation and Nonlinear Evolution of the Seasonally Modulated South Pacific Subtropical Countercurrent. Journal Of Physical Oceanography 38, 1515-1528, doi:10.1175/2007JPO3856.1.

42. Qiu, B. \& Chen, S. (2004). Seasonal Modulations in the Eddy Field of the South Pacific Ocean. Journal of Physical Oceanography 34, 1515-1527, doi:10.1175/15200485(2004)034<1515:SMITEF>2.0.CO;2.

43. Qiu, B. \& Chen, S. (2006). Decadal Variability in the Large-Scale Sea Surface Height Field of the South Pacific Ocean: Observations and Causes. Journal of Physical Oceanography 36, 1751-1762, doi:10.1175/JPO2943.1.

44. Meredith, M. P. \& Hogg, A. M. (2006). Circumpolar response of Southern Ocean eddy activity to a change in the Southern Annular Mode. Geophysical Research Letters 33, L16608, doi:10.1029/2006g1026499.

45. Morrow, R., Ward, M. L., Hog, A. M. \& Pasquet, S. (2010). Eddy response to Southern Ocean climate modes. Journal of Geophysical Research, in press, doi:10.1029/2009JC005894.
46. McClean, J. L., Poulain, P.-M., Pelton, J. W. \& Maltrud, M. E. (2002). Eulerian and Lagrangian Statistics from Surface Drifters and a High-Resolution POP Simulation in the North Atlantic. Journal Of Physical Oceanography 32, 2472-2491.

47. Zhurbas, V. \& Oh, I. S. (2004). Drifter-derived maps of lateral diffusivity in the Pacific and Atlantic Oceans in relation to surface circulation patterns. J. Geophys. Res. 109, C05015, doi:10.1029/2003jc002241.

48. Lumpkin, R. \& Pazos, M. (2006). Measuring surface currents with Surface Velocity Program drifters: the instrument, its data, and some recent results. In Lagrangian Analysis and Prediction of Coastal and Ocean Dynamics (LAPCOD). Eds. A. Griffa et al. Ch. 2, Cambridge University Press, Cambridge.

49. CTOH (2009). Global Surface Currents. Centre de Topographie des Oceans et de l'Hydrosphere. <http://ctoh.legos.obs-mip.fr/products/global-surfacecurrents $>$ (accessed September, 2009).

50. Sudre, J. \& Morrow, R. (2008). Global surface currents: a high-resolution product for investigating ocean dynamics. Ocean Dyn. 58, 101-118.

51. NOAA (2010). Ocean Surface Current Analyses - Real Time (OSCAR). NOAA. $<$ http://www.oscar.noaa.gov/> (accessed January, 2010).

52. Ambe, D., Endoh, T., Hibiya, T. \& Imawaki, S. (2009). Transition to the large meander path of the Kuroshio as observed by satellite altimetry. La Mer 47, 19-27.

53. Chelton, D. B., Schlax, M. G., Samelson, R. M. \& de Szoeke, R. A. (2007). Global observations of large oceanic eddies. Geophysical Research Letters 34, L15606, doi:10.1029/2007gl030812.

54. Spadone, A. \& Provost, C. (2009). Variations in the Malvinas Current volume transport since October 1992. J. Geophys. Res. 114, C02002, doi:10.1029/2008jc004882.

55. Ridgway, K. R. \& Dunn, J. R. (2003). Mesoscale structure of the mean East Australian Current System and its relationship with topography. Progress In Oceanography 56, 189-222.

56. Beal, L. M., Chereskin, T. K., Lenn, Y. D. \& Elipot, S. (2006). The Sources and Mixing Characteristics of the Agulhas Current. Journal Of Physical Oceanography 36, 2060-2074, doi:10.1175/JPO2964.1.

57. Maltrud, M. E. \& McClean, J. L. (2005). An eddy resolving global $1 / 10^{\circ}$ ocean simulation. Ocean Modelling 8, 31-54. 
58. Reason, C. J. C. (2001). Evidence for the Influence of the Agulhas Current on Regional Atmospheric Circulation Patterns. Journal Of Climate 14, 2769-2778.

59. Minobe, S., Kuwano-Yoshida, A., Komori, N., Xie, S.-P. \& Small, R. J. (2008). Influence of the Gulf Stream on the troposphere. Nature 452, 206-209,

doi:10.1038/nature06690

http://www.nature.com/nature/journal/v452/n7184/supp info/nature06690.html.

60. Chelton, D. B., Schlax, M. G., Freilich, M. H. \& Milliff, R. F. (2004). Satellite Measurements Reveal Persistent Small-Scale Features in Ocean Winds. Science 303, 978-983, doi:10.1126/science.1091901.

61. Kelly, K. \& Dong, S. (2004). The relationship of western boundary current heat transport and storage to midlatitude ocean-atmosphere interaction. In Earth's Climate: The Ocean-Atmosphere Interaction, Geophysical Monograph Series, Vol. 147. Eds. C. Z. Wang, S.-P. Xie, \& J. A. Carton. American Geophysical Union, Washington D.C., 347-363.

62. Elipot, S. \& Lumpkin, R. (2008). Spectral description of oceanic near-surface variability. Geophysical Research Letters 35, L05606, doi:10.1029/2007gl032874.

63. Chaigneau, A., Pizarro, O. \& Rojas, W. (2008). Global climatology of near-inertial current characteristics from Lagrangian observations. Geophysical Research Letters 35, L13603, doi:10.1029/2008g1034060.

64. Maximenko, N. A. \& Hafner, J. (2010). SCUD: Surface CUrrents from Diagnostic model. IPRC Technical Note $\mathbf{5}, 17$

65. Marshall, J. \& Schott, F. (1999). Open-Ocean Convection: Observations, Theory, and Models. Rev. Geophys. 37, 1-64, doi:10.1029/98rg02739.

66. Walin, G. (1982). On the relation between sea-surface heat flow and thermal circulation in the ocean. Tellus 34, 187-195.

67. Risien, C. M. \& Chelton, D. B. (2008). A Global Climatology of Surface Wind and Wind Stress Fields from Eight Years of QuikSCAT Scatterometer Data. Journal Of Physical Oceanography 38, 2379-2413, doi:10.1175/2008JPO3881.1.

68. Taylor, P. K. (2000). Intercomparison and validation of ocean-atmosphere energy flux fields - Final report of the Joint WCRP/SCOR Working Group on Air-Sea Fluxes. WCRP No. 112, 306 pp.

69. Yu, L. \& Weller, R. A. (2007). Objectively Analyzed Air-Sea Heat Fluxes for the Global Ice-Free Oceans (1981-2005). Bull. Amer. Meteorol. Soc. 88, 527-539, doi:10.1175/BAMS-88-4-527.
70. Large, W. \& Yeager, S. (2009). The global climatology of an interannually varying air-sea flux data set. Climate Dynamics 33, 341-364.

71. Speer, K. \& Tziperman, E. (1992). Rates of Water Mass Formation in the North Atlantic Ocean. Journal of Physical Oceanography 22, 93-104.

72. Marshall, J., Jamous, D. \& Nilsson, J. (1999). Reconciling thermodynamic and dynamic methods of computation of water-mass transformation rates. Deep Sea Research Part I: Oceanographic Research Papers 46, 545-572.

73. Climode et al. (2009). The Climode Field Campaign: Observing the Cycle of Convection and Restratification over the Gulf Stream. Bull. Amer. Meteorol. Soc. 90, 1337-1350, doi:10.1175/2009BAMS2706.1.

74. Kara, A. B., Rochford, P. A. \& Hurlburt, H. E. (2003). Mixed layer depth variability over the global ocean. $J$. Geophys. Res. 108, 3079, doi:10.1029/2000jc000736.

75. de Boyer Montégut, C., Madec, G., Fischer, A. S., Lazar, A. \& Iudicone, D. (2004). Mixed layer depth over the global ocean: An examination of profile data and a profile-based climatology. J. Geophys. Res. 109, C12003, doi:10.1029/2004jc002378.

76. Davis, R. E. (2005). Intermediate-Depth Circulation of the Indian and South Pacific Oceans Measured by Autonomous Floats. Journal Of Physical Oceanography 35, 683-707, doi:10.1175/JPO2702.1.

77. Argo (2010). Argo Information Centre. JCOMMOPS. <http://wo.jcommops.org/cgi-bin/WebObjects/Argo > (accessed May 10, 2010).

78. Yashayaev, I. (2007). Hydrographic changes in the Labrador Sea, 1960-2005. Progress In Oceanography 75, 857-859.

79. Stommel, H. (1979). Determination of water mass properties of water pumped down from the Ekman layer to the geostrophic flow below. Proceedings of the National Academy of Sciences of the United States of America 76, 3051-3055.

80. Luyten, J. R., Pedlosky, J. \& Stommel, H. (1983). The Ventilated Thermocline. Journal Of Physical Oceanography 13, 292-309.

81. Woods, J. (1985). The physics of thermocline ventilation. In Coupled Atmosphere-Ocean Models. Ed. J. C. Nihoul. Elsevier, Amsterdam, 543-590.

82. Jenkins, W. J. (1998). Studying subtropical thermocline ventilation and circulation using tritium and $3 \mathrm{He} . J$. Geophys. Res. 103, 15817-15831, doi:10.1029/98jc00141. 
83. O'Connor, B. M., Fine, R. A., Maillet, K. A. \& Olson, D. B. (2002). Formation rates of subtropical underwater in the Pacific Ocean. Deep-Sea Research Part IOceanographic Research Papers 49, 1571-1590.

84. Rudnick, D. L. (1996). Intensive surveys of the Azores Front 2. Inferring the geostrophic and vertical velocity fields. J. Geophys. Res. 101, 16291-16303, doi:10.1029/96jc01144.

85. Lee, C. M. (2006). Intermediate water formation at the Japan/East Sea subpolar front. Oceanography 19, 5464.

86. Joyce, T. M., Thomas, L. N. \& Bahr, F. (2009). Wintertime observations of Subtropical Mode Water formation within the Gulf Stream. Geophysical Research Letters 36, L02607, doi:10.1029/2008g1035918.

87. Rhein, M. et al. (2010). Upwelling and associated heat flux in the equatorial Atlantic inferred from helium isotope disequilibrium. J. Geophys. Res. 115, C08021, doi:10.1029/2009jc005772.

88. Fox-Kemper, B., Ferrari, R. \& Hallberg, R. (2008). Parameterization of Mixed Layer Eddies. Part I: Theory and Diagnosis. Journal Of Physical Oceanography 38, 1145-1165, doi:10.1175/2007JPO3792.1.

89. Fox-Kemper, B. \& Ferrari, R. (2008). Parameterization of Mixed Layer Eddies. Part II: Prognosis and Impact. Journal Of Physical Oceanography 38, 1166-1179, doi:10.1175/2007JPO3788.1.

90. Capet, X., McWilliams, J. C., Molemaker, M. J. \& Shchepetkin, A. F. (2008). Mesoscale to Submesoscale Transition in the California Current System. Part III: Energy Balance and Flux. Journal Of Physical Oceanography 38, 2256-2269, doi:10.1175/2008JPO3810.1.

91 .Fine, R. A., Rhein, M. \& Andriè, C. (2002). Using a CFC effective age to estimate propagation and storage of climate anomalies in the deep western North Atlantic Ocean. Geophysical Research Letters 29, 2227, doi:10.1029/2002g1015618.

92. Levitus, S., Antonov, J. \& Boyer, T. (2005). Warming of the world ocean, 1955-2003. Geophysical Research Letters 32, L02604, doi:10.1029/2004g1021592.

93. Domingues, C. M. et al. (2008). Improved estimates of upper-ocean warming and multi-decadal sea-level rise. Nature 453, 1090-1093, doi:http://www.nature.com/nature/journal/v453/n7198/ suppinfo/nature07080_S1.html.

94. Boyer, T. P., Levitus, S., Antonov, J. I., Locarnini, R. A. \& Garcia, H. E. (2005). Linear trends in salinity for the World Ocean, 1955-1998. Geophysical Research Letters 32, L01604, doi:10.1029/2004g1021791.
95. Reverdin, G. et al. (2002). Recent changes in the surface salinity of the North Atlantic subpolar gyre. $J$. Geophys. Res. 107, 8010, doi:10.1029/2001jc001010.

96. Dickson, R. R., Curry, R. \& Yashayaev, I. (2003). Recent changes in the North Atlantic. Philos. Trans. R. Soc. Lond. Ser. A-Math. Phys. Eng. Sci. 361, 1917-1933.

97 .Hughes, S. L., Holliday, N. P. \& Beszczynska-Möller, A. (2008). ICES Report on Ocean Climate 2007. ICES Cooperative Research Report No. 291, 64 pp. $<$ http://www.noc.soton.ac.uk/ooc/ICES_WGOH/iroc.p $\underline{\mathrm{hp}}>$.

98. Deutsch, C., Emerson, S. \& Thompson, L. (2005). Fingerprints of climate change in North Pacific oxygen. Geophysical Research Letters 32, L16604, doi:10.1029/2005g1023190.

99. Johnson, G. C. \& Gruber, N. (2007). Decadal water mass variations along $20^{\circ} \mathrm{W}$ in the Northeastern Atlantic Ocean. Progress In Oceanography 73, 277-295.

100. Aoki, S., Yoritaka, M. \& Masuyama, A. (2003). Multidecadal warming of subsurface temperature in the Indian sector of the Southern Ocean. Journal Of Geophysical Research-Oceans 108.

101. Stramma, L., Johnson, G. C., Sprintall, J. \& Mohrholz, V. (2008). Expanding Oxygen-Minimum Zones in the Tropical Oceans. Science 320, 655-658, doi:10.1126/science. 1153847.

102. Bopp, L., LeQuéré, C., Heimann, M., Manning, A. C. \& Monfray, P. (2002). Climate-induced oceanic oxygen fluxes: Implications for the contemporary carbon budget. Global Biogeochem. Cycles 16, 1022, doi:10.1029/2001gb001445.

103. Keeling, R. F., Körtzinger, A. \& Gruber, N. (2010). Ocean Deoxygenation in a Warming World. Annual Review of Marine Science 2, 199-229, doi:doi:10.1146/annurev.marine.010908.163855.

104. Brandt, P. et al. (2010). Changes in the ventilation of the oxygen minimum zone of the tropical North Atlantic. Journal Of Physical Oceanography 40, doi:10.1175/2010JPO4301.1.

105. LeQuéré, C. et al. (2003). Two decades of ocean CO2 sink and variability. Tellus B 55, 649-656.

106. Kawano, T. et al. (2006). Bottom water warming along the pathway of lower circumpolar deep water in the Pacific Ocean. Geophysical Research Letters 33, L23613, doi:10.1029/2006gl027933.

107. Purkey, S. G. \& Johnson, G. C. (2010). Antarctic Bottom Water warming between the 1990s and the 2000s: Contributions to global heat and sea level rise budgets. Journal of Climate, doi:10.1175/2010JCLI3682.1, submitted. 
108. Bindoff, N. L. et al. (2007). Observations: Oceanic Climate Change and Sea Level. In Climate Change 2007: The Physical Science Basis. Contribution of Working Group I to the Fourth Assessment Report of the Intergovernmental Panel on Climate Change. Eds. S. Solomon et al. Cambridge University Press Cambridge and New York, 385-432.

109. Curry, R., Dickson, B. \& Yashayaev, I. (2003). A change in the freshwater balance of the Atlantic Ocean over the past four decades. Nature 426, 826-829.

110. Fine, R. A., Maillet, K. A., Sullivan, K. F. \& Willey, D. (2001). Circulation and Ventilation flux of the Pacific Ocean. J. Geophys. Res. 106, 22159-22178, doi:10.1029/1999jc000184.

111. Rhein, M. et al. (2002). Labrador Sea Water: Pathways, CFC Inventory, and Formation Rates. Journal of Physical Oceanography 32, 648-665.

112. Orsi, A. H., Johnson, G. C. \& Bullister, J. L. (1999). Circulation, mixing, and production of Antarctic Bottom Water. Progress In Oceanography 43, 55-109.

113. Smethie, W. M., Jr. \& Fine, R. A. (2001). Rates of North Atlantic Deep Water formation calculated from chlorofluorocarbon inventories. Deep-Sea Research Part I-Oceanographic Research Papers 48, 189-215.

114. LeBel, D. A. et al. (2008). The formation rate of North Atlantic Deep Water and Eighteen Degree Water calculated from CFC-11 inventories observed during WOCE. Deep Sea Research Part I: Oceanographic Research Papers 55, 891-910.

115. Sabine, C. L. et al. (2004). The oceanic sink for anthropogenic CO2. Science 305, 367-371.

116. Willey, D. A. et al. (2004). Global oceanic chlorofluorocarbon inventory. Geophysical Research Letters 31, L01303, doi:10.1029/2003gl018816.

117. Kieke, D. et al. (2007). Changes in the pool of Labrador Sea Water in the subpolar North Atlantic. Geophysical Research Letters 34, L06605, doi:10.1029/2006gl028959.chlorofluorocarbon inventories. Deep-Sea Research Part I-Oceanographic Research Papers 48, 189-215. 